\title{
Colloid-Facilitated Solute Transport in Variably Saturated Porous Media: Numerical Model and Experimental Verification
}

\author{
Jirka Šimůnek,* Changming He, Liping Pang, and S. A. Bradford
}

\begin{abstract}
Strongly sorbing chemicals (e.g., heavy metals, radionuclides, pharmaceuticals, and explosives) in porous media are associated predominantly with the solid phase, which is commonly assumed to be stationary. However, recent field- and laboratory-scale observations have shown that in the presence of mobile colloidal particles (e.g., microbes, humic substances, clays, and metal oxides), colloids can act as pollutant carriers and thus provide a rapid transport pathway for strongly sorbing contaminants. To address this problem, we developed a one-dimensional numerical model based on the HYDRUS-1D software package that incorporates mechanisms associated with colloid and colloid-facilitated solute transport in variably saturated porous media. The model accounts for transient variably saturated water flow, and for both colloid and solute movement due to advection, diffusion, and dispersion, as well as for solute movement facilitated by colloid transport. The colloid transport module additionally considers the processes of attachment/detachment to/from the solid phase and/or the air-water interface, straining, and/or size exclusion. Various blocking and depth dependent functions can be used to modify the attachment and straining coefficients. The solute transport module uses the concept of two-site sorption to describe nonequilibrium adsorption-desorption reactions to the solid phase. The module further assumes that contaminants can be sorbed onto surfaces of both deposited and mobile colloids, fully accounting for the dynamics of colloid movement between different phases. Application of the model is demonstrated using selected experimental data from published saturated column experiments, conducted to investigate the transport of $\mathrm{Cd}$ in the presence of Bacillus subtilis spores in alluvial gravel aquifer media. Numerical results simulating bacteria transport, as well as the bacteria-facilitated $\mathrm{Cd}$ transport, are compared with experimental results. A sensitivity analysis of the model to various parameters is also presented.
\end{abstract}

\begin{abstract}
OLlOIDAl PARTICles (e.g., humic substances, clays, metal oxides, and microorganisms) are commonly found in subsurface environments (Kretzschmar et al., 1999). Many contaminants can sorb onto colloids in suspension, thereby increasing their concentrations in solution beyond thermodynamic solubilities (Kim et al., 1992). Experimental evidence now exists that many contaminants are transported not only in a dissolved state by water, but also sorbed to moving colloids. This colloidfacilitated transport has been illustrated in the literature for numerous contaminants, including heavy metals (Grolimund et al., 1996), radionuclides (Von Gunten

J. Šimůnek and C. He, Dep. of Environmental Sciences, Univ. of California Riverside, CA 92521; L. Pang, Institute of Environmental Science \& Research, Christchurch, NZ; S.A. Bradford, George E. Brown Jr. Salinity Laboratory, USDA, ARS, Riverside, CA 92521. Received 22 Dec. 2005. *Corresponding author (Jiri.Simunek@ucr.edu).
\end{abstract}

Published in Vadose Zone Journal 5:1035-1047 (2006).

Original Research

doi:10.2136/vzj2005.0151

(c) Soil Science Society of America

677 S. Segoe Rd., Madison, WI 53711 USA et al., 1988; Noell et al., 1998), pesticides (Vinten et al., 1983; Kan and Tomson, 1990; Lindqvist and Enfield, 1992), pharmaceuticals (Tolls, 2001; Thiele-Bruhn, 2003), hormones (Hanselman et al., 2003), and other contaminants (Magee et al., 1991; Mansfeldt et al., 2004). Since mobile colloids often move at rates similar or faster as nonsorbing tracers, the potential of enhanced transport of colloid-associated contaminants can be very significant (e.g., McCarthy and Zachara, 1989). Failure to account for colloid-facilitated solute transport can severely underestimate the transport potential and risk assessment for these contaminants. Models that can accurately describe the various mechanisms controlling colloid and solute transport, and their mutual interactions and interactions with the solid phase, are essential for improving predictions of colloid-facilitated transport of solutes in variably saturated porous media.

The transport behavior of dissolved contaminant species has been studied for many years. By comparison, colloid transport and the mutual interactions among contaminants, colloids, and porous media are less well understood. While colloids are subject to similar subsurface fate and transport processes as chemical compounds, they are also subject to their own unique complexities (van Genuchten and Šimůnek, 2004). Since many colloids and microbes are negatively charged, they are electrostatically repelled by negatively-charged solid surfaces. This will lead to an anion exclusion process that can cause slightly enhanced transport relative to fluid flow. The advective transport of colloids may similarly be enhanced by size exclusion, which limits their presence to the larger pores (Bradford et al., 2003, 2006). In addition to being subject to adsorption-desorption process at solid surfaces, colloids are also affected by straining in the porous matrix (Bradford et al., 2003, 2006) and may accumulate at airwater interfaces (Wan and Wilson, 1994; Thompson and Yates, 1999; Wan and Tokunaga, 2002). All of these additional complexities require colloid transport models to be more flexible than regular solute transport models.

Models that consider colloid-facilitated solute transport are based on mass balance equations for all colloid and contaminant species. The various colloid-facilitated solute transport models that have appeared in the literature differ primarily in the manner which colloid transport and contaminant interactions are handled. For example, Mills et al. (1991) and Dunnivant et al. (1992) assume that colloids are nonreactive with the solid phase, Corapcioglu and Jiang (1993) and Jiang and Corapcioglu (1993) consider a first-order kinetic attachment of colloids, Saiers and Hornberger (1996) consider an irreversible nonlinear kinetic attachment of colloids, and van de Weerd and Leijnse (1997) describe colloid attachment kinetics using the Langmuir equation. All colloidfacilitated transport models account for interactions be- 
tween the contaminants and colloids. Various equilibrium and kinetic models have been used for this purpose.

Although already relatively complex, no existing model for colloid-facilitated solute transport to our knowledge includes all of the major processes contributing to colloid and colloid-facilitated solute transport. For example, the majority of models for colloid-facilitated solute transport consider flow and transport only in fully saturated groundwater systems, usually for steady-state flow, and thus do not account for colloid interactions with the air-water interface. Also, no colloid-facilitated transport model has considered straining and size exclusion as mechanisms of colloid retention and transport, respectively. These two processes, and especially straining, have recently received much attention since classical colloid transport models are often unable to describe simultaneously both breakthrough curves vs. time and concentration profiles vs. depth (Bradford et al., 2003, 2006; Li et al., 2004; Tufenkji and Elimelech, 2005).

Straining involves the entrapment of colloids in downgradient pores that are too small to allow particle passage. The critical pore size for straining will depend on the size of the colloid and the pore-size distribution of the medium (McDowell-Boyer et al., 1986; Bradford et al., 2002, 2003). Straining may have significant implications for colloid-facilitated solute transport, as illustrated by Bradford et al. (2006). Considering average capillary pressure-saturation curves for the 12 major soil textural groups given by Carsel and Parrish (1988), they calculated that a $2 \mu \mathrm{m}$ colloid, which is the size of a clay particle, will be excluded or strained in 10 to $86 \%$ of the soil pore space for the various soil textures (Bradford et al., 2006). These percentages should significantly increase if the soils become unsaturated.

Size exclusion, a process closely related to straining, affects the mobility of colloids by constraining them to flow domains and pore networks that are physically accessible (Ryan and Elimelech, 1996; Ginn, 2002). Electrostatic forces also play an important role in the distribution (and mobility) of colloids. Anionic colloids will be excluded from locations adjacent to negatively charged solid surfaces; similar to the much reported anion exclusion process for anionic solutes (Krupp, 1972; Gvirtzman and Gorelick, 1991; Ginn, 1995). In case of size or anion exclusion, colloids will tend to reside in larger pores and in more conductive parts of the flow domain. As a result, colloids will be transported faster than a conservative solute tracer (Reimus, 1995; Cumbie and McKay, 1999; Harter et al., 2000; Bradford et al., 2004). Differences in the dispersive flux for colloids and a conservative solute tracer are also anticipated as a result of exclusion (Scheibe and Wood, 2003). Bradford et al. (2002) observed that the dispersivity of $3.2 \mu \mathrm{m}$ carboxyl latex colloids was up to seven times greater than bromide in saturated aquifer sand. Conversely, Sinton et al. (2000) found in a field microbial transport experiment that the apparent colloid dispersivity decreased with increasing particle size.

Colloid and colloid-facilitated contaminant transport in partially saturated porous media is even more complex than in water-saturated systems. In addition to all of the processes and difficulties discussed above, colloid trans- port in partially saturated porous media is further complicated by the presence of an air phase and thin water films, in addition to the solid and water phases present in saturated media. Wan and Wilson (1994) observed that colloidal particles deposit preferentially on the air-water interface via a capillary force acting on the particles, and that particle transport was tremendously retarded since the air-water interface acted as a strong sorption phase. Another physical restriction on colloid transport in unsaturated systems is imposed by thin water films; this process is often referred to as film straining (Wan and Tokunaga, 1997; Saiers and Lenhart, 2003). Wan and Tokunaga (1997) proposed that colloid transport in unsaturated systems depends on the ratio of the colloid size to water film thickness. Corapcioglu and Choi (1996) developed a mathematical model describing colloid transport in unsaturated porous media, and also studied the effect of colloids on volatile contaminant transport and air-water partitioning in unsaturated porous media.

Most current models for colloid-facilitated solute transport assume that the number of colloids with respect to contaminant is large and that kinetic reactions coefficients are not dependent on the number of colloids in the system. Although this may be true for some systems, the number of colloids (or concentrations) is often highly variable, with colloids being mobilized (or immobilized) due to changing chemical or hydrological conditions. Thus the reaction coefficients need to be adjusted to the number of colloids in the system in different phases (i.e., mobile, immobile, attached to the air-water interface). This adjustment needs to be performed also for numerical stability reasons. For example, if the number of colloids in the system decreases dramatically and the sorption constants for solute to colloids are assumed to be constant, this may lead to large sorbed concentrations, and hence numerical instabilities.

In this study we developed a one-dimensional numerical model based on the HYDRUS-1D software package that incorporates processes associated with colloid and colloidfacilitated solute transport in variably saturated porous media. The model accounts for both colloid and solute movement due to advection, diffusion, and dispersion in variably saturated soils, as well as for solute movement facilitated by colloid transport. The colloid transport module additionally considers the processes of attachment/detachment to/from the solid phase and/or the airwater interface, straining, and/or size exclusion. The model allows for different pore water velocities and dispersivities for colloids and solute. In this paper we first present the model itself, provide information about the numerical techniques used to solve the governing equations, and provide a simple application of the model to laboratory data. We also present a brief sensitivity analysis of the model to selected transport and reaction parameters.

\section{CONCEPTUAL MODEL}

The conceptual model of colloid and colloid facilitated solute transport (Fig. 1) is based on several assumptions. We assume that the porous medium consists of three phases, that is, solid phase, air, and water. Ac- 

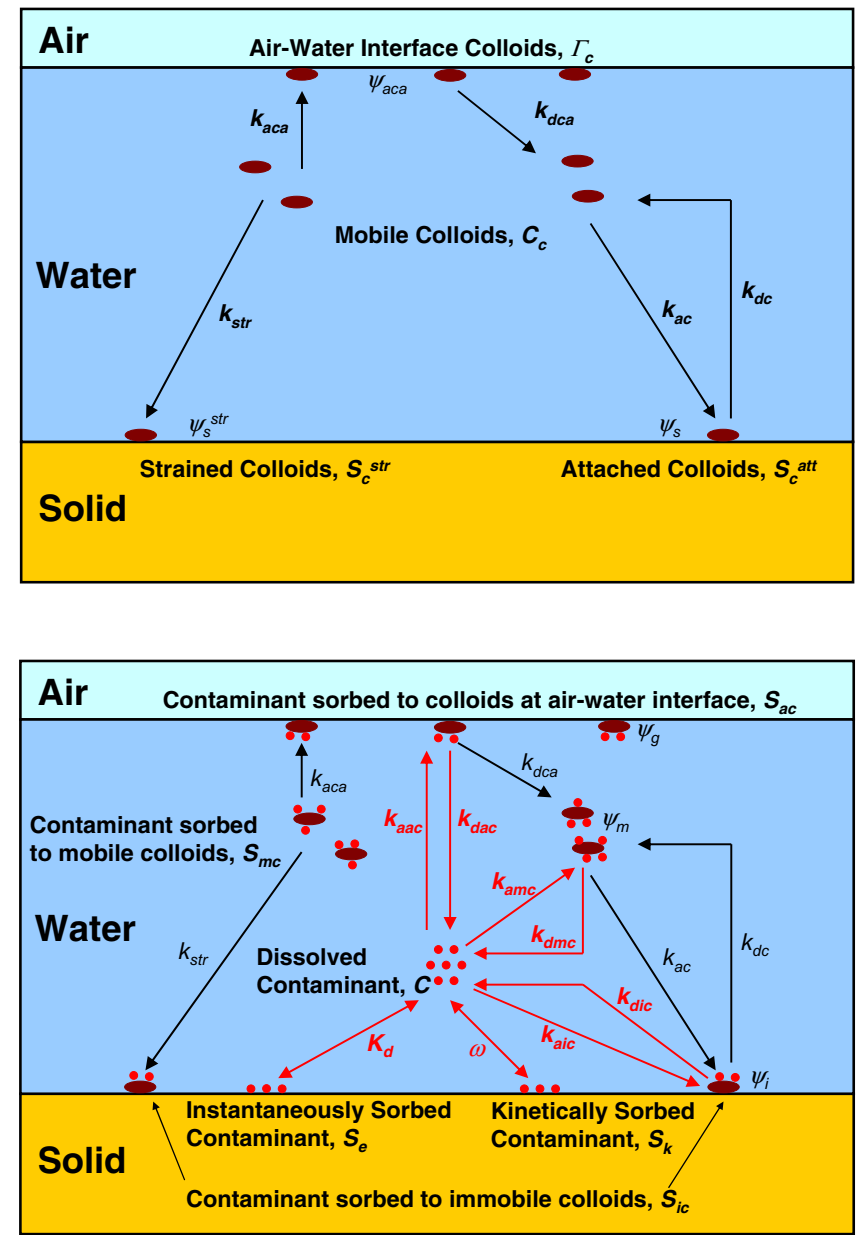

Fig. 1. Schematic of the (top) colloid transport and (bottom) colloidfacilitated solute transport model.

cording to van de Weerd and Leijnse (1997), it is assumed that (a) only one type of colloids exists in the system that these colloids can be described by their mean behavior, (b) colloids are stable and that their mutual interactions in the liquid phase may be neglected, (c) immobile colloids do not affect the flow and transport properties of the porous medium because of their clogging of small pores, and (d) the transport of colloids is not affected by sorption of contaminants on colloids. We further assume that colloids exist in four states: mobile (suspended in water), attached to the solid phase, strained by the solid phase, and attached to the air-water interface (Fig. 1 top, Table 1). We further assume that colloid phase changes can be described using nonlinear first-order processes.

We further assume that contaminants can be dissolved in the liquid phase, as well as sorbed instantaneously and kinetically to the solid phase, and to colloids in all of their states. We thus distinguish six different states of contaminants (Fig. 1 bottom; Table 1): dissolved, instantaneously or kinetically sorbed to the solid phase, sorbed to mobile or immobile colloids (either strained or/attached to the solid phase), and colloids attached to the air-water interface. The coefficients $k$ in Fig. 1 (Table 2) represent various firstorder attachment/detachment or sorption/desorption rates, the coefficients $K_{\mathrm{d}}$ and $\omega$ represent instantaneous
Table 1. Species considered in the colloid and colloid-facilitated solute transport model ( $\mathrm{L}$ is the length unit, $\mathrm{M}$ is the mass unit, and $\mathbf{n}$ is the number of colloids).

\begin{tabular}{|c|c|c|}
\hline Species description & Variable & Units \\
\hline \multicolumn{3}{|l|}{ Colloid species } \\
\hline Mobile colloids & $C_{\mathrm{c}}$ & $\mathbf{n} \mathbf{L}^{-3}$ \\
\hline Colloids attached to the solid phase & $S_{\mathrm{c}}^{\text {att }}$ & $\mathbf{n} \mathbf{M}^{-1}$ \\
\hline Strained colloids & $S_{\mathrm{c}}^{\text {str }}$ & $\mathbf{n} \mathbf{M}^{-1}$ \\
\hline $\begin{array}{l}\text { Colloids attached to the } \\
\text { air-water interface }\end{array}$ & $\Gamma_{\mathrm{c}}$ & $\mathbf{n} \mathbf{L}^{-2}$ \\
\hline \multicolumn{3}{|l|}{ Solute (contaminant) species } \\
\hline Dissolved contaminant & $C$ & $\mathbf{M ~ L ~}_{-1}^{-3}$ \\
\hline $\begin{array}{l}\text { Contaminant instantaneously sorbed } \\
\text { to the solid phase }\end{array}$ & $S_{\mathrm{e}}$ & $\mathbf{M} \mathbf{M}^{-1}$ \\
\hline $\begin{array}{l}\text { Contaminant kinetically sorbed to the } \\
\text { solid phase }\end{array}$ & $S_{\mathrm{k}}$ & $\mathbf{M} \mathbf{M}^{-1}$ \\
\hline $\begin{array}{l}\text { Contaminant sorbed to } \\
\text { mobile colloids }\end{array}$ & $S_{\mathrm{mc}}$ & $\mathbf{M n}^{-1}$ \\
\hline $\begin{array}{l}\text { Contaminant sorbed to } \\
\text { immobile colloids }\end{array}$ & $S_{\text {ic }}$ & $M_{n}{ }^{-1}$ \\
\hline $\begin{array}{l}\text { Contaminant sorbed to colloids } \\
\text { attached to the air-water interface }\end{array}$ & $S_{\mathrm{ac}}$ & $\mathbf{M n}^{-1}$ \\
\hline
\end{tabular}

and kinetic solute sorption to the solid phase, respectively, while the factors $\psi$ account for nonlinearity of the process.

\section{MATHEMATICAL MODEL Variably Saturated Water Flow}

Transient one-dimensional variably saturated water flow in porous media is described using the Richards equation (Richards, 1931):

$$
\frac{\partial \theta}{\partial t}=\frac{\partial}{\partial x}\left[K\left(\frac{\partial h}{\partial x}+\cos \alpha\right)\right]-S
$$

where $h$ is the water pressure head [L], $\theta$ is the volumetric water content $\left[\mathrm{L}^{3} \mathrm{~L}^{-3}\right], t$ is time $[\mathrm{T}], x$ is the spatial coordinate [L] (positive upward), $S$ is the sink term $\left[\mathrm{L}^{3} \mathrm{~L}^{-3} \mathrm{~T}^{-1}\right], \alpha$ is the angle between the flow direction and the vertical axis, and $K(h)$ is the unsaturated hydraulic conductivity function $\left[\mathrm{L} \mathrm{T}^{-1}\right]$. The soil hydraulic properties, that is, the retention curve $\theta(h)$ and the unsaturated hydraulic conductivity function $K(h)$ can be evaluated using, for example, the analytical model of van Genuchten (1980).

Table 2. Kinetic reactions considered in the colloid and colloidfacilitated solute transport model ( $T$ is the time unit).

\begin{tabular}{|c|c|c|}
\hline Reaction description & Variable & Units \\
\hline \multicolumn{3}{|l|}{ Colloid species } \\
\hline Colloids attachment coefficient & $\boldsymbol{k}_{\mathrm{ac}}$ & $\mathbf{T}_{-1}^{-1}$ \\
\hline Colloids detachment coefficient & & $\mathbf{T}_{-1}^{-1}$ \\
\hline Colloids straining coefficient & $k_{\mathrm{str}}$ & $\mathbf{T}^{-1}$ \\
\hline $\begin{array}{l}\text { Colloids attachment coefficient to the } \\
\text { air-water interface }\end{array}$ & $k_{\text {aca }}$ & $\mathbf{T}^{-\mathbf{1}}$ \\
\hline $\begin{array}{l}\text { Colloids detachment coefficient from } \\
\text { the air-water interface }\end{array}$ & $k_{\text {dca }}$ & $\mathbf{T}^{-1}$ \\
\hline \multicolumn{3}{|l|}{ Solute (contaminant) species } \\
\hline $\begin{array}{l}\text { Solute adsorption rate to } \\
\text { mobile colloids }\end{array}$ & $k_{\text {amc }}$ & $\mathbf{T}^{-\mathbf{1}}$ \\
\hline $\begin{array}{l}\text { Solute desorption rate from } \\
\text { mobile colloids }\end{array}$ & $k_{\mathrm{dmc}}$ & $\mathbf{T}^{-\mathbf{1}}$ \\
\hline $\begin{array}{l}\text { Solute adsorption rate to } \\
\text { immobile colloids }\end{array}$ & $\boldsymbol{k}_{\text {aic }}$ & $\mathbf{T}^{-1}$ \\
\hline $\begin{array}{l}\text { Solute desorption rate from } \\
\text { immobile colloids }\end{array}$ & $k_{\text {dic }}$ & $\mathbf{T}^{-\mathbf{1}}$ \\
\hline $\begin{array}{l}\text { Solute adsorption rate to colloids at } \\
\text { the air-water interface }\end{array}$ & $k_{\text {aac }}$ & $\mathbf{T}^{-\mathbf{1}}$ \\
\hline $\begin{array}{l}\text { Solute desorption rate from colloids at } \\
\text { the air-water interface }\end{array}$ & $k_{\text {dac }}$ & $\mathbf{T}^{-\mathbf{1}}$ \\
\hline
\end{tabular}




\section{Colloid Transport}

Colloid fate and transport models are commonly based on some form of the advection-dispersion equation, but modified to account for colloid filtration (Harvey and Garabedian, 1991; Hornberger et al., 1992; Corapcioglu and Choi, 1996; Bradford et al., 2003). A more comprehensive equation for colloid transport describing both colloid/matrix and colloid/air-water interface mass partitioning in one-dimensional form is given by

$$
\begin{aligned}
\frac{\partial \theta_{\mathrm{w}} C_{\mathrm{c}}}{\partial t} & +\rho \frac{\partial S_{\mathrm{c}}}{\partial t}+\frac{\partial A_{\mathrm{aw}} \Gamma_{\mathrm{c}}}{\partial t}=\frac{\partial}{\partial x}\left(\theta_{\mathrm{w}} D_{\mathrm{c}} \frac{\partial C_{\mathrm{c}}}{\partial x}\right) \\
& -\frac{\partial q_{\mathrm{c}} C_{\mathrm{c}}}{\partial x}+R_{\mathrm{c}}
\end{aligned}
$$

where $C_{\mathrm{c}}$ is the colloid concentration in the aqueous phase [n L ${ }^{-3}$ ], $S_{\mathrm{c}}$ and $\Gamma_{\mathrm{c}}$ are colloid concentrations adsorbed to the solid phase $\left[\mathrm{nm}^{-1}\right]$ and air-water interface $\left[\mathrm{n} \mathrm{L}^{-2}\right]$, respectively; $\theta_{\mathrm{w}}$ is the volumetric water content accessible to colloids $\left[\mathrm{L}^{3} \mathrm{~L}^{-3}\right]$ (due to ion or size exclusion, $\theta_{\mathrm{w}}$ may be smaller than the total volumetric water content $\theta$ ), $D_{\mathrm{c}}$ is the dispersion coefficient for colloids $\left[\mathrm{L}^{2} \mathrm{~T}^{-1}\right], \rho$ is the bulk density $\left[\mathrm{M} \mathrm{L}^{-3}\right], A_{\text {aw }}$ is the air-water interfacial area per unit volume $\left[\mathrm{L}^{2} \mathrm{~L}^{-3}\right], q_{\mathrm{c}}$ is the volumetric water flux density for colloids [ $\mathrm{L} \mathrm{T}^{-1}$ ], while $R_{\mathrm{c}}$ represents various chemical and biological reactions $\left[\mathrm{nL}^{-3} \mathrm{~T}^{-1}\right]$. The second and third terms on the left side of Eq. [2] represent colloid mass-transfer terms between the aqueous phase and the solid phase or the air-water interface $\left[\mathrm{n} \mathrm{L}^{-3} \mathrm{~T}^{-1}\right]$, respectively. The first two terms on the right side of Eq. [2] represent the dispersive and advective colloid fluxes, respectively. The value of $\theta_{\mathrm{w}}$ is defined as

$$
\theta_{\mathrm{w}}=\theta-\varepsilon \gamma
$$

where $\varepsilon$ is porosity (equal to the saturated water content, $\left.\theta_{\mathrm{s}}\right)\left[\mathrm{L}^{3} \mathrm{~L}^{-3}\right]$ and $\gamma$ is the water saturation that is not accessible to mobile colloids [-] (Bradford et al., 2006). The volumetric water flux density for colloids, $q_{\mathrm{c}}$, moving only in pores from which they are not excluded, can be calculated from the ratio of the relative hydraulic conductivity of the entire pore space $\left(K_{\mathrm{rw}}\right)$ to the relative hydraulic conductivity of the colloid-accessible pores $\left(K_{\mathrm{rc}}\right)$

$$
q_{\mathrm{c}}=q \frac{K_{\mathrm{rc}}}{K_{\mathrm{rw}}}
$$

where $q$ is the volumetric water flux density for water [L $\mathrm{T}^{-1}$. The relative hydraulic conductivity of the colloidaccessible pores, $K_{\mathrm{rc}}[-]$, can then be calculated using, for example, the pore-size distribution model of Burdine (1953) by adjusting its limits of integration to reflect water flow to straining sites (Bradford et al., 2003) as

$$
K_{\mathrm{rc}}=S_{\mathrm{w}}^{2} \frac{\int_{\gamma}^{S_{\mathrm{w}}} \frac{\mathrm{d} S_{\mathrm{w}}}{\left[h\left(S_{\mathrm{w}}\right)\right]^{2}}}{\int_{0}^{1} \frac{\mathrm{d} S_{\mathrm{w}}}{\left[h\left(S_{\mathrm{w}}\right)\right]^{2}}} \quad S_{\mathrm{w}}>\gamma
$$

Colloid mass transfer between the aqueous and solid phases is traditionally described using attachmentdetachment models of the form:

$$
\rho \frac{\partial S_{\mathrm{c}}}{\partial t}=\theta_{\mathrm{w}} \psi_{\mathrm{s}} f_{\mathrm{s}} k_{\mathrm{ac}} C_{\mathrm{c}}-\rho k_{\mathrm{dc}} S_{\mathrm{c}}-R_{\mathrm{sc}}
$$

where $R_{\mathrm{sc}}$ represents various chemical and biological reactions acting on colloids that are kinetically attached to the matrix $\left[\mathrm{n} \mathrm{L}^{-3} \mathrm{~T}^{-1}\right], k_{\mathrm{ac}}$ and $k_{\mathrm{dc}}$ are the first-order colloid attachment and detachment coefficients $\left[\mathrm{T}^{-1}\right]$, respectively, $\psi_{\mathrm{s}}$ is a dimensionless colloid retention function [-], and $f_{\mathrm{s}}$ is the fraction of the solid surface area that is available for attachment. The attachment coefficient is generally calculated using filtration theory (Logan et al., 1995), a quasi-empirical formulation in terms of the median grain diameter of the porous medium (often termed the collector), the pore-water velocity, and collector and collision (or sticking) efficiencies accounting for colloid removal due to diffusion, interception and gravitational sedimentation (Rajagopalan and Tien, 1976; Logan et al., 1995; Tufenkji and Elimelech, 2004). The first-order detachment coefficient in Eq. [6] accounts for colloid mobilization, presumably as affected by changes in pore-water chemistry (ionic strength, ionic composition, and $\mathrm{pH}$ ) and physical perturbations in flow, including changes in the flow rate and the water content.

To simulate reductions in the attachment coefficient due to filling of favorable sorption sites, $\psi_{\mathrm{s}}$ is sometimes assumed to decrease with increasing colloid mass retention. Random sequential adsorption (Johnson and Elimelech, 1995) and Langmuirian dynamics (Adamczyk et al., 1994) equations have been proposed for $\psi_{\mathrm{s}}$ to describe this blocking phenomenon, with the latter equation given by:

$$
\psi_{\mathrm{s}}=1-\frac{S_{\mathrm{c}}}{S_{\mathrm{c}}^{\max }}
$$

in which $S_{\mathrm{c}}{ }^{\max }$ is the maximum solid-phase colloid concentration $\left[\mathrm{n} \mathrm{M}^{-1}\right]$. Conversely, enhanced colloid retention during porous-medium ripening can theoretically be described using a functional form of $\psi_{\mathrm{s}}$ that increases with increasing mass of retained colloids (Tien, 1989; Tien and Chiang, 1985; Deshpande and Shonnard, 1999) We refer to several recent studies (Ginn, 2002; DeNovio et al., 2004; Rockhold et al., 2004) for more detailed discussions of the attachment and detachment coefficients in Eq. [6].

The first term on the right side of Eq. [6] is multiplied by the fraction of the solid surface area, $f_{\mathrm{s}}$, that is available for attachment. Since mobile colloids are due to size exclusion transported in only a fraction of the pore space $\left(S_{\mathrm{w}}-\gamma\right)$, only a portion of the solid surface area is accessible for attachment. The fraction of the solid surface area that is available for attachment can be estimated as (Bradford et al., 2006):

$$
f_{\mathrm{s}}=\frac{\int_{\gamma}^{S_{\mathrm{w}}} h\left(S_{\mathrm{w}}\right) \mathrm{d} S_{\mathrm{w}}}{\int_{0}^{1} h\left(S_{\mathrm{w}}\right) \mathrm{d} S_{\mathrm{w}}}
$$

where $S_{\mathrm{w}}$ is the soil water saturation [-]. 
Notice that Eq. [6] lumps the effects of a variety of physical and chemical processes into a single attachmentcoefficient parameter. The attachment coefficient in Eq. [6] has been found to depend strongly on water content, with attachment significantly increasing as the water content decreases. This has been attributed to a variety of processes, including interfacial attachment and film straining. Bradford et al. (2002, 2003, 2006) hypothesized that the influence of straining and attachment mechanisms on colloid retention should be separated into two distinct components: attachment and detachment per se, and straining (being the entrapment of colloids in pore throats that are too small to allow passage). They modeled the influence of straining using an irreversible firstorder expression as follows:

$$
\begin{aligned}
\rho \frac{\partial S_{\mathrm{c}}}{\partial t}= & \rho \frac{\partial S_{\mathrm{c}}^{\mathrm{str}}}{\partial t}+\rho \frac{\partial S_{\mathrm{c}}^{\mathrm{att}}}{\partial t}=\theta_{\mathrm{w}} \psi_{\mathrm{s}}^{\mathrm{str}} k_{\mathrm{str}} C_{\mathrm{c}} \\
& +\left(\theta_{\mathrm{w}} \psi_{\mathrm{s}} f_{\mathrm{s}} k_{\mathrm{ac}} C_{\mathrm{c}}-\rho k_{\mathrm{dc}} S_{\mathrm{c}}\right)-R_{\mathrm{sc}}
\end{aligned}
$$

where $k_{\text {str }}$ is the first-order straining coefficient $\left[\mathrm{T}^{-1}\right]$, and $S_{\mathrm{c}}^{\text {str }}$ and $S_{\mathrm{c}}^{\text {att }}$ are the solid-phase concentrations of strained and attached colloids [ $\mathrm{n} \mathrm{M}^{-1}$ ], respectively. The first term on the right-hand side of the above equation now accounts for straining and the second term (in parentheses) for attachment-detachment.

Application of the first-order attachment-detachment model given by Eq. [6] typically leads to exponential colloid distributions vs. depth. Bradford et al. (2003) showed that such exponential distributions are often inconsistent with experimental data. They obtained much better results using a depth-dependent straining coefficient $\psi_{\mathrm{s}}^{\text {str }}$ in Eq. [9] of the form

$$
\psi_{\mathrm{s}}^{\mathrm{str}}=\left(\frac{d_{50}+x}{d_{50}}\right)^{-\beta}
$$

where $d_{50}$ is the median grain size of the porous media $[\mathrm{L}], \beta$ is a fitting parameter [-], and $x$ is distance from the porous-medium inlet [L]. Data from Bradford et al. (2002, 2003) for different colloid diameters $\left(d_{\mathrm{p}}\right)$ and porous media median grain sizes showed an optimal value of 0.43 for $\beta$, while $k_{\text {str }}$ could be described using a unique increasing function of the ratio of $d_{\mathrm{p}} / d_{50}$. Subsequent studies with layered soils (Bradford et al., 2004) showed the importance of straining at and close to textural interfaces when flow occurs in the direction of coarse-textured to medium- and fine-textured media. Straining was found to be a significant mechanism for colloid retention for values of $d_{\mathrm{p}} / d_{50}$ greater than 0.005 .

Finally, a model similar to Eq. [6] may be used to describe the partitioning of colloids to the air-water interface

$$
\frac{\partial A_{\mathrm{aw}} \Gamma_{\mathrm{c}}}{\partial t}=\theta_{\mathrm{w}} \psi_{\mathrm{aca}} f_{\mathrm{a}} k_{\mathrm{aca}} C_{\mathrm{c}}-A_{\mathrm{aw}} k_{\mathrm{dca}} \Gamma_{\mathrm{c}}-R_{\text {aca }}
$$

where $\Gamma_{\mathrm{c}}$ is the colloid concentration adsorbed to the airwater interface $\left[\mathrm{n} \mathrm{L}^{-2}\right], R_{\text {aca }}$ represents various chemical and biological reactions of attached colloids to the airwater interface $\left[\mathrm{n} \mathrm{L}^{-3} \mathrm{~T}^{-1}\right], A_{\text {aw }}$ is the air-water interfacial area per unit volume $\left[\mathrm{L}^{2} \mathrm{~L}^{-3}\right], \psi_{\text {aca }}$ is a dimensionless colloid retention function for the air-water interface [-] similarly as used in Eq. [6], and $f_{\mathrm{a}}$ is the fraction of the air-water interfacial area that is available for attachment [-], and $k_{\text {aca }}$ and $k_{\mathrm{dca}}$ are the first-order colloid attachment and detachment coefficients to/from the air-water interface $\left[\mathrm{T}^{-1}\right]$, respectively. The interfacial area model of Bradford and Leij (1997) can be used to estimate the air-water interfacial area $A_{\mathrm{a}}$ w as:

$$
A_{\mathrm{aw}}=-\frac{\varepsilon}{\sigma_{\mathrm{aw}}} \int_{1}^{S_{\mathrm{w}}} P_{\mathrm{aw}}(S) \mathrm{d} S=\frac{\varepsilon \rho_{\mathrm{w}} g}{\sigma_{\mathrm{aw}}} \int_{S_{\mathrm{w}}}^{1} h(S) \mathrm{d} S
$$

where $\varepsilon$ is the porosity $\left[\mathrm{L}^{3} \mathrm{~L}^{-3}\right], P_{\text {aw }}$ and $\sigma_{\text {aw }}$ are the airwater capillary pressure $\left[\mathrm{M} \mathrm{L}^{-1} \mathrm{~T}^{-2}\right]$ and surface tension $\left[\mathrm{M} \mathrm{T}^{-2}\right]$, respectively; $h$ is the pressure head $[\mathrm{L}], \rho_{\mathrm{w}}$ is the density of water $\left[\mathrm{M} \mathrm{L}^{-3}\right]$, and $g$ is the gravitational acceleration $\left[\mathrm{L} \mathrm{T}^{-2}\right]$.

\section{Colloid-Facilitated Solute Transport}

Colloid-facilitated solute transport model requires knowledge of colloid transport, dissolved contaminant transport, and colloid-facilitated contaminant transport, and of various interactions between colloids, solute, soil, and air phase. Transport and/or mass-balance equations must therefore be formulated for the total contaminant, for contaminant sorbed kinetically or instantaneously to the solid phase, and for contaminant sorbed to mobile colloids, to colloids attached to the soil solid phase, and to colloids accumulated at the air-water interface, that is, for contaminant in all different phases or pools.

Our colloid-facilitated transport model closely follows development of many similar models (e.g., Corapcioglu and Jiang, 1993; Jiang and Corapcioglu, 1993; Saiers and Hornberger, 1996; van de Weerd and Leijnse, 1997; Bekhit and Hassan, 2005). Major differences in our model include consideration of water contents, water fluxes, and air-water interfacial areas that may change in time and space (i.e., transient variably-saturated water flow), the presence of colloids on the air-water interface, and adjustment of all kinetic rates to the number of colloids present in the system.

\section{Mass-Balance Equation for the Total Contaminant}

The combined dissolved and colloid-facilitated contaminant transport equation (in one dimension) is given by:

$$
\begin{aligned}
\frac{\partial \theta C}{\partial t}+ & \rho \frac{\partial S_{\mathrm{e}}}{\partial t}+\rho \frac{\partial S_{\mathrm{k}}}{\partial t}+\frac{\partial \theta_{\mathrm{w}} C_{\mathrm{c}} S_{\mathrm{mc}}}{\partial t}+\rho \frac{\partial S_{\mathrm{c}} S_{\mathrm{ic}}}{\partial t}+\frac{\partial A_{\mathrm{aw}} \Gamma_{\mathrm{c}} S_{\mathrm{ac}}}{\partial t} \\
= & \frac{\partial}{\partial x}\left(\theta D \frac{\partial C}{\partial x}\right)-\frac{\partial q C}{\partial x}+\frac{\partial}{\partial x}\left(\theta_{\mathrm{w}} S_{\mathrm{mc}} D_{\mathrm{c}} \frac{\partial C_{\mathrm{c}}}{\partial x}\right) \\
& -\frac{\partial q_{\mathrm{c}} C_{\mathrm{c}} S_{\mathrm{mc}}}{\partial x}+R
\end{aligned}
$$

where $C$ is the dissolved-contaminant concentration in the aqueous phase $\left[\mathrm{M} \mathrm{L}^{-3}\right], S_{\mathrm{e}}$ and $S_{\mathrm{k}}$ are contaminant concentrations sorbed instantaneously and kinetically, respectively, to the solid phase [ $\left.\mathrm{M} \mathrm{M}^{-1}\right], S_{\mathrm{mc}}, S_{\mathrm{ic}}$, and $S_{\mathrm{ac}}$ are contaminant concentrations sorbed to mobile and immobile (attached to solid and air-water interface) colloids $\left[\mathrm{M} \mathrm{n}^{-1}\right]$, respectively; $D$ is the dispersion coefficient for contaminants in solution $\left[\mathrm{L}^{2} \mathrm{~T}^{-1}\right], q$ is the volumetric water density for the contaminant $\left[\mathrm{L} \mathrm{T}^{-1}\right]$, and $R$ represents various chemical and biological reac- 
tions, such as degradation and production $\left[\mathrm{M} \mathrm{L}^{-3} \mathrm{~T}^{-1}\right]$, discussed below. Note that the left-hand side sums the mass of contaminant associated with the different phases (contaminant in the liquid phase, contaminant sorbed instantaneously or kinetically to the solid phase, and contaminant sorbed to mobile colloids and immobile colloids attached to solid phase or air-water interface), while the right-hand side considers various spatial mass fluxes (dispersion and advective transport of the dissolved contaminant, as well as dispersion and advective transport of contaminant sorbed to mobile colloids) and sink/ source reactions.

\section{Mass-Balance Equation for Contaminant Sorbed to the Solid Phase}

Eq. [13] invokes the concept of two-site sorption for modeling non-equilibrium adsorption-desorption reactions (e.g., van Genuchten and Wagenet, 1989). The two-site sorption concept assumes that total sorption, $S$, can be divided into two fractions:

$$
S=S_{\mathrm{e}}+S_{\mathrm{k}}
$$

with sorption $S_{\mathrm{e}}\left[\mathrm{M} \mathrm{M}^{-1}\right]$ on one fraction of the sites (type-1 sites) assumed to be instantaneous, and sorption $S_{\mathrm{k}}\left[\mathrm{M} \mathrm{M}^{-1}\right]$ on the remaining sites (type-2 sites) being time dependent according to

$$
\rho \frac{\partial S_{\mathrm{k}}}{\partial t}=\omega\left[(1-f) \Psi(C)-S_{\mathrm{k}}\right]+R_{\mathrm{sk}}
$$

where $\omega$ is the first-order rate constant $\left[\mathrm{T}^{-1}\right], f$ is the fraction of exchange sites assumed to be in equilibrium with the solution phase [-], $\Psi(C)$ is the adsorption isotherm $\left[\mathrm{M} \mathrm{M}^{-1}\right]$ that can be expressed using Freundlich, Langmuir, Freundlich-Langmuir, or linear adsorption models (Šimůnek et al., 1998), and $R_{\text {sk }}$ represents various chemical and biological reactions of the kinetically sorbed contaminant $\left[\mathrm{M} \mathrm{L}^{-3} \mathrm{~T}^{-1}\right]$.

\section{Mass-Balance Equation for Contaminant Sorbed to Mobile Colloids}

The mass-balance equation for contaminant sorbed to mobile colloids can be written as

$$
\begin{aligned}
\frac{\partial \theta_{\mathrm{w}} C_{\mathrm{c}} S_{\mathrm{mc}}}{\partial t}= & \frac{\partial}{\partial x}\left(\theta_{\mathrm{w}} S_{\mathrm{mc}} D_{\mathrm{c}} \frac{\partial C_{\mathrm{c}}}{\partial x}\right)-\frac{\partial q_{\mathrm{c}} C_{\mathrm{c}} S_{\mathrm{mc}}}{\partial x}+\theta \psi_{\mathrm{m}} k_{\mathrm{amc}} C \\
& -\theta_{\mathrm{w}} k_{\mathrm{dmc}} C_{\mathrm{c}} S_{\mathrm{mc}}-\theta_{\mathrm{w}}\left(\psi_{\mathrm{s}} f_{\mathrm{s}} k_{\mathrm{ac}}+\psi_{\mathrm{str}} k_{\mathrm{str}}\right) C_{\mathrm{c}} S_{\mathrm{mc}} \\
& +\rho k_{\mathrm{dc}} S_{\mathrm{c}} S_{\mathrm{ic}}-\theta_{\mathrm{w}} \psi_{\mathrm{aca}} f_{\mathrm{a}} k_{\mathrm{aca}} C_{\mathrm{c}} S_{\mathrm{mc}} \\
& +A_{\mathrm{aw}} k_{\mathrm{dca}} \Gamma_{\mathrm{c}} S_{\mathrm{ac}}+R_{\mathrm{mc}}
\end{aligned}
$$

where $k_{\text {amc }}$ is the adsorption rate to mobile colloids $\left[\mathrm{T}^{-1}\right], k_{\mathrm{dmc}}$ is the desorption rate from mobile colloids $\left[\mathrm{T}^{-1}\right]$, and $R_{\mathrm{mc}}$ represents various chemical and biological reactions for contaminant sorbed to mobile colloids $\left[\mathrm{M} \mathrm{L}^{-3} \mathrm{~T}^{-1}\right]$. The parameter $\psi_{\mathrm{m}}$ adjusts the sorption rate to the number of mobile colloids present, that is,

$$
\psi_{\mathrm{m}}=C_{\mathrm{c}} / C_{\mathrm{c}}^{\mathrm{ref}}
$$

where $C_{\mathrm{c}}{ }^{\text {ref }}$ is the reference concentration of colloids for which the sorption rate $k_{\mathrm{amc}}$ is valid [ $\left.\mathrm{M} \mathrm{L}^{-3}\right]$. In Eq. [16], the first two terms on the right-hand side represent dispersive and advective transport, respectively, of contaminant sorbed to mobile colloids; the third and fourth terms account for sorption and desorption of contaminants to/from mobile colloids, respectively; the fifth and sixth terms account for the attachment (including straining) and detachment of mobile colloids containing sorbed contaminants, respectively; the seventh and eighth terms account for the attachment and detachment of mobile colloids containing sorbed contaminants to/from air-water interface, respectively; while the ninth term represents degradation or other reactions involving contaminant sorbed to mobile colloids.

\section{Mass-Balance Equation for Contaminant Sorbed to Immobile Colloids}

The mass-balance equation for contaminant sorbed to immobile colloids can be written as follows

$$
\begin{aligned}
\rho \frac{\partial S_{\mathrm{c}} S_{\mathrm{ic}}}{\partial t}= & \theta \psi_{\mathrm{i}} k_{\mathrm{aic}} C-\rho k_{\mathrm{dic}} S_{\mathrm{c}} S_{\mathrm{ic}} \\
& +\theta_{\mathrm{w}}\left(\psi_{\mathrm{s}} f_{\mathrm{s}} k_{\mathrm{ac}}+\psi_{\mathrm{str}} k_{\mathrm{str}}\right) C_{\mathrm{c}} S_{\mathrm{mc}} \\
& -\rho k_{\mathrm{dc}} S_{\mathrm{c}} S_{\mathrm{ic}}+R_{\mathrm{ic}}
\end{aligned}
$$

where $k_{\text {aic }}$ is the adsorption rate to immobile colloids $\left[\mathrm{T}^{-1}\right], k_{\mathrm{dic}}$ is the desorption rate from immobile colloids $\left[\mathrm{T}^{-1}\right]$, and $R_{\mathrm{ic}}$ represents various reactions for contaminant sorbed to immobile colloids $\left[\mathrm{M} \mathrm{L}^{-3} \mathrm{~T}^{-1}\right]$. The parameter $\psi_{\mathrm{i}}$ adjusts the sorption rate to the number of immobile colloids present:

$$
\psi_{\mathrm{i}}=S_{\mathrm{c}} / S_{\mathrm{c}}^{\mathrm{ref}}
$$

where $S_{\mathrm{c}}{ }^{\text {ref }}$ is the reference concentration of immobile colloids for which the sorption rate $k_{\text {aic }}$ is valid $\left[\mathrm{nm}^{-1}\right]$. In Eq. [18] the first two terms on the right-hand side represent adsorption and desorption of contaminant to/ from immobile colloids, respectively; the third and fourth terms describe the attachment (including straining) and detachment of immobile colloids with sorbed contaminant, respectively; and the fifth term represents reactions of contaminant sorbed to immobile colloids.

\section{Mass-Balance Equation for Contaminant Sorbed to Colloids Attached to the Air-Water Interface}

The mass-balance equation for contaminant sorbed to colloids attached to the air-water interface may be written as

$$
\begin{aligned}
\frac{\partial A_{\mathrm{aw}} \Gamma_{\mathrm{c}} S_{\mathrm{ac}}}{\partial t}= & \theta \psi_{\mathrm{g}} k_{\mathrm{acc}} C-A_{\mathrm{aw}} k_{\mathrm{dac}} \Gamma_{\mathrm{c}} S_{\mathrm{ac}} \\
& +\theta_{\mathrm{w}} \psi_{\mathrm{aca}} f_{\mathrm{a}} k_{\mathrm{aca}} C_{\mathrm{c}} S_{\mathrm{mc}}-A_{\mathrm{aw}} k_{\mathrm{dca}} \Gamma_{\mathrm{c}} S_{\mathrm{ac}}+R_{\mathrm{ac}}
\end{aligned}
$$

where $k_{\text {aac }}$ is the adsorption rate to colloids at the airwater interface $\left[\mathrm{T}^{-1}\right], k_{\mathrm{dac}}$ is the desorption rate from colloids at the air-water interface $\left[\mathrm{T}^{-1}\right]$, and $R_{\mathrm{ac}}$ represents various reactions for contaminant sorbed to colloids at the air-water interface $\left[\mathrm{M} \mathrm{L}^{-3} \mathrm{~T}^{-1}\right]$. Similarly as in Eq. [19], the parameter $\psi_{\mathrm{g}}$ adjusts the sorption rate to the number of colloids at the air-water interface:

$$
\psi_{\mathrm{g}}=\Gamma_{\mathrm{c}} / \Gamma_{\mathrm{c}}^{\mathrm{ref}}
$$


where $\Gamma_{\mathrm{c}}^{\text {ref }}$ is the reference concentration of immobile colloids for which sorption rate $k_{\text {aac }}$ is valid $\left[\mathrm{nL}^{-2}\right]$. In Eq. [20] the first two terms on the right-hand side represent the sorption and desorption, respectively, of contaminant to/from colloids at the air-water interface; the third and fourth terms account for the attachment and detachment, respectively, of colloids with sorbed contaminant to/from the air-water interface; whereas the fifth term represents degradation and other reactions of contaminant sorbed to colloids accumulated at the air-water interface.

\section{Reaction Term}

The reaction term $R$ in Eq. [13] may be used to account for a variety of chemical and biological reactions and transformations, including degradation and production, not already explicitly incorporated in the main total contaminant mass transport equation. In the newly developed colloid-facilitated solute transport module we do not fully support current capabilities of the HYDRUS software package to simulate sequential first-order decay chains and can simulate transport of only one single compound. The reaction term $R$ may thus include provisions for only one first-order degradation reaction that may have different rate coefficients in each phase (i.e., in the liquid, sorbed, and colloid phase). The reaction term $R$ in Eq. [13] for colloidfacilitated transport scenarios is now given by:

$$
\begin{aligned}
R= & -\mu_{\mathrm{w}} \theta C-\mu_{\mathrm{s}} \rho\left(S_{\mathrm{k}}+S_{\mathrm{e}}\right) \\
& -\mu_{\mathrm{c}}\left(\theta_{\mathrm{w}} C_{\mathrm{c}} S_{\mathrm{mc}}+\rho S_{\mathrm{c}} S_{\text {ic }}+A_{\mathrm{aw}} \Gamma_{\mathrm{c}} S_{\mathrm{ac}}\right)
\end{aligned}
$$

where $\mu_{\mathrm{w}}, \mu_{\mathrm{s}}$, and $\mu_{\mathrm{c}}$ are first-order rate constants $\left[\mathrm{T}^{-1}\right]$ for solutes in the liquid, solid, and colloid phases, respectively. Note that we assume that the solute degradation rate is the same for solute sorbed to all colloid, that is, mobile and immobile.

The terms $R_{\mathrm{sk}}, R_{\mathrm{mc}}, R_{\mathrm{ic}}$, and $R_{\mathrm{ac}}$ for reactions in the kinetically sorbed phase, on mobile colloids and on colloids associated either with the solid phase or the airwater interface, respectively, are as follows:

$$
\begin{aligned}
R_{\mathrm{sk}} & =-\mu_{\mathrm{s}} \rho S_{\mathrm{k}} \\
R_{\mathrm{mc}} & =-\mu_{\mathrm{c}} \theta_{\mathrm{w}} C_{\mathrm{c}} S_{\mathrm{mc}} \\
R_{\mathrm{ic}} & =-\mu_{\mathrm{c}} \rho S_{\mathrm{c}} S_{\mathrm{ic}} \\
R_{\mathrm{ac}} & =-\mu_{\mathrm{c}} A_{\mathrm{aw}} \Gamma_{\mathrm{c}} S_{\mathrm{ac}}
\end{aligned}
$$

\section{SOLUTION OF THE GOVERNING EQUATIONS}

The above mathematical development shows that a complete description of colloid-facilitated solute transport requires, in addition to variably-saturated flow equation, a total of nine coupled partial differential equations involving nine unknown variables $\left(C_{\mathrm{c}}, S_{\mathrm{c}}{ }^{s t r}\right.$, $S_{\mathrm{c}}{ }^{a t t}, \Gamma_{\mathrm{c}}, C, S_{\mathrm{k}}, S_{\mathrm{mc}}, S_{\mathrm{ic}}$, and $\left.S_{\mathrm{ac}}\right)$. Four partial-differential equations pertain to four forms of colloids, that is, mobile colloids $\left(C_{\mathrm{c}}\right)$, strained colloids $\left(S_{\mathrm{c}}^{\text {str }}\right)$, attached colloids to the solid phase $\left(S_{\mathrm{c}}{ }^{a t t}\right)$, and colloids attached to the air-water interface $\left(\Gamma_{\mathrm{c}}\right)$. Additional five partialdifferential equations pertain to five forms of contami- nants, that is, dissolved contaminant $(C)$, contaminant kinetically sorbed to the solid phase $\left(S_{\mathrm{k}}\right)$, contaminant sorbed to mobile colloids $\left(S_{\mathrm{mc}}\right)$, contaminant sorbed to colloids associated with the solid phase $\left(S_{\text {ic }}\right)$, and contaminant sorbed to colloids attached to the airwater interface $\left(S_{\mathrm{ac}}\right)$. Note that the instantaneously sorbed contaminant does not need a special partial differential equation, since it is described by the algebraic equation (adsorption isotherm) and treated simultaneously with the dissolved contaminant.

To find a solution for the flow Eq. [1] and the nine transport equations (Eq. [2], [6], [9], [11], [13], [15], [16], [18], and [20]) analytically is difficult, if not impossible. Numerical methods hence must be used to solve the flow and transport equations. Our numerical solution was implemented into the HYDRUS-1D software package (Šimůnek et al., 1998). The numerical solution is performed at each time step in three sequential steps.

First, because of the assumption that colloids do not affect the flow and transport properties of the porous medium, the variably-saturated flow Eq. [1] can be solved independently of the colloid and solute transport equations. Had we considered the effect of attached and strained colloids on the hydraulic conductivity (i.e., clogging), the soil hydraulic properties would have had to be updated at each time step depending on the number of strained and attached colloids. HYDRUS-1D uses a mass-lumped linear finite elements scheme for the spatial discretization and a fully implicit finite difference scheme for the temporal discretization (Šimůnek et al., 1998). The mixed form of the nonlinear Richards Eq. [1] was solved with a Picard iterative solution scheme. After achieving convergence, the nodal values of the fluid flux are determined from nodal values of the pressure head by applying Darcy's law, and together with nodal values of the water content subsequently used as input to the numerical solution of the colloid transport and colloidfacilitated solute transport equations.

Second, because of the assumption that the transport of colloids is not affected by sorption of contaminants on colloids, the four partial differential equations describing colloid transport can be solved independently of the five solute transport equations. The four governing equations $(2,6,9$, and 11$)$ form a linear system when the dimensionless colloid retention functions $\psi_{\mathrm{s}}, \psi_{\mathrm{s}}{ }^{\text {str }}$, and $\psi_{\text {aca }}$ are equal to one (i.e., when blocking and depthdependent phenomena are not considered). In that case, Eq. [6], [9], and [11], none of which contains spatial derivatives, are discretized using finite differences, similarly as for physical nonequilibrium solute transport in Šimůnek et al. (1998), and incorporated directly into the discretized form of Eq. [2]. The Galerkin finite element method (spatial discretization) coupled with the Crank-Nicholson finite difference method (temporal discretization) was used to solve the colloid transport Eq. [2] subject to appropriate initial and boundary conditions. When the dimensionless colloid retention functions $\psi_{\mathrm{s}}, \psi_{\mathrm{s}}^{\text {str }}$, and $\psi_{\mathrm{aca}}$ are not equal to one (i.e., when blocking or depth-dependent processes are considered), then the system of equations is nonlinear. For those cases we used a Picard iterative solution 
scheme to solve the system of nonlinear equations. Again, after the solution of the colloid transport equations is obtained, nodal values of colloid concentrations in the different states (e.g., mobile, strained, and/or attached) are used as input to the numerical solution of the colloid-facilitated solute transport equations.

Finally, a Picard iterative solution scheme was used to solve the system of five equations describing colloidfacilitated solute transport $(13,15,16,18$, and 20). We used again the finite element method for spatial discretization (of 13 and 15) and finite difference method for temporal discretization (of all five equations). After achieving convergence, and hence the solute concentrations of the different phases, the numerical solution can proceed to the next time step, starting again with the Richards equation.

\section{MODEL VERIFICATION}

We selected experimental data of Pang et al. (2005) to test our colloid- and colloid-facilitated solute transport model. In Pang et al. (2005), a column experiment was conducted to study the movement of $\mathrm{Cd}$ in the presence of Bacillus subtilis spores under saturated flow conditions. The column (18 cm long, $10 \mathrm{~cm}$ i.d.) was uniformly packed with coarse gravel aquifer material $\left(d_{50}=16.69 \mathrm{~mm}, d_{60} / d_{10}=53\right)$, which gave bulk density of $1.9 \mathrm{~g} \mathrm{~cm}^{-3}$ and an effective porosity of 0.27 . A solution (at fixed $\mathrm{pH}$ ) containing approximately $4 \mathrm{mg} \mathrm{L}^{-1}$ of $\mathrm{Cd}$ and $2 \mathrm{mg} \mathrm{L}^{-1}$ of $\mathrm{Br}$ was first injected for about $1 \mathrm{~h}$ (5 pore-volumes). Bacillus subtilis spores were subsequently introduced to the column, along with $\mathrm{Cd}$ and $\mathrm{Br}$, for another $40 \mathrm{~min}$ (3.4 pore-volumes). After that, the column was flushed with fresh water. A constant flow rate was applied during the entire experiment. Untreated groundwater extracted from alluvial gravel aquifers was used as the background electrolyte. Detailed information is given in Pang et al. (2005).

Figure 2 shows the observed breakthrough curves (BTCs) of $\mathrm{Br}$, B. subtilis spores and Cd from the column experiment. Although $\mathrm{Br}$ and $\mathrm{Cd}$ solutes were injected simultaneously in the beginning of the experiment, the $\mathrm{BTC}$ of Cd showed a slow increase of concentrations com-

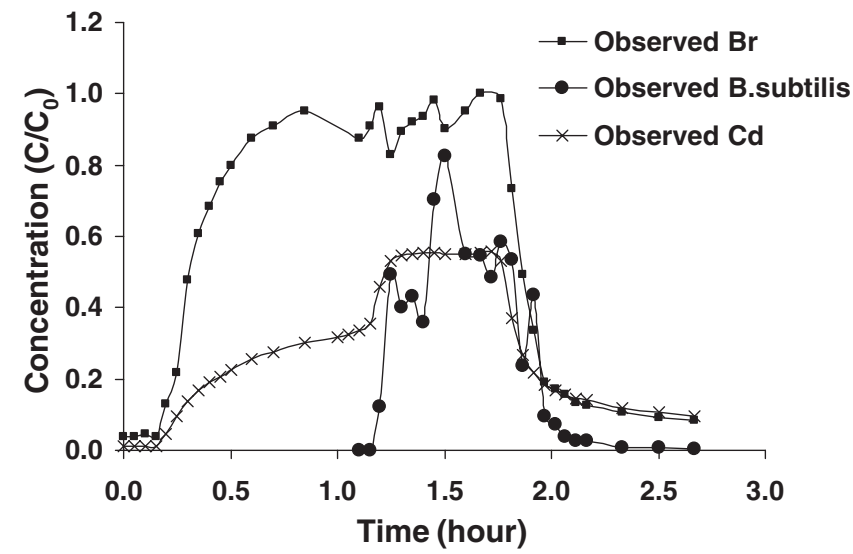

Fig. 2. Observed Br, Bacillus subtilis spores, and Cd breakthrough curves for the column experiment of Pang et al. (2005). pared to the BTC of $\mathrm{Br}$, which suggests a higher adsorption capability of $\mathrm{Cd}$ onto the solid matrix. After injection of the spores, a simultaneous steep rise and flat plateau of both B. subtilis spores and Cd occurred. This observation implies that $\mathrm{Cd}$ was co-transported with the spores.

The column experiment was simulated in three steps (Pang and Šimůnek, 2006). First, the Br breakthrough curve was used to optimize the pore-water velocity and longitudinal dispersivity. Next, the $B$. subtilis breakthrough curve was used to optimize the first-order attachment and detachment coefficients, while the porewater velocity and longitudinal dispersivity were fixed at the values determined for Br. Finally, the $\mathrm{Cd}$ breakthrough curve was analyzed to obtain the distribution coefficient, the first-order rate constant for exchanging between two sorption sites, and the adsorption and desorption rate coefficients to/from immobile bacteria. Pang and Šimůnek (2006) independently determined adsorption and desorption rate coefficients to/from mobile bacteria from a batch kinetic study in the absence of aquifer media. Results of preliminary simulations suggest that almost all $\mathrm{Cd}$ sorption sites of the solid phase were kinetic. These rate coefficients, together with parameters for the bacteria and flow, were fixed during simulations of the Cd data. Parameters were optimized using the internal HYDRUS optimization routine (Marquardt, 1963) for the $\mathrm{Br}$ and bacteria data and the PEST software (Doherty, 1994) for the Cd data. The optimized parameters are given in Table 3, while a comparison of modelpredicted results and observed experimental data is presented in Fig. 3. Notice an excellent correspondence between optimized and measured breakthrough curves for all three compounds. Since the column experiment was conducted under saturated condition, the simulation did not consider the attachment-detachment of colloids to/ from the air-water interface. As we assumed the same pore-water velocity and dispersion for $\mathrm{Br}$ and the bacteria, size exclusion was also not considered here. Pang and Šimůnek (2006) provide more details about

Table 3. Transport and reaction parameters used to simulate the Br, Bacillus subtilis spores, and Cd breakthrough curves presented in Fig. 3.

\begin{tabular}{|c|c|c|}
\hline Description & Parameter & Value \\
\hline \multicolumn{3}{|l|}{$\underline{\text { Br tracer parameters }}$} \\
\hline $\begin{array}{l}\text { Saturated water content } \\
\text { Saturated hydraulic conductivity, } \mathrm{cm} \mathrm{h}^{-1} \\
\text { Bulk density, g } \mathrm{cm}^{-3} \\
\text { Longitudinal dispersivity, } \mathrm{cm} \\
\text { Saturation }\end{array}$ & $\begin{array}{l}\theta_{\mathrm{s}} \\
K_{\mathrm{s}} \\
\rho \\
\alpha_{\mathbf{L}} \\
\mathbf{S w}\end{array}$ & $\begin{array}{c}0.27 \\
16.7 \\
1.9 \\
0.9 \\
1.0\end{array}$ \\
\hline \multicolumn{3}{|l|}{ Colloid (Bacillus subtilis spores) parameters } \\
\hline $\begin{array}{l}\text { First-order colloid attachment coefficient, } h^{-1} \\
\text { First-order colloid detachment coefficient, } h^{-1} \\
\text { Water saturation that is not accessible to mobile } \\
\text { colloids }\end{array}$ & $\begin{array}{l}\boldsymbol{k}_{\mathrm{ac}} \\
\boldsymbol{k}_{\mathrm{ddc}} \\
\gamma\end{array}$ & $\begin{array}{l}\text { 1.697 } \\
0.0001 \\
0\end{array}$ \\
\hline \multicolumn{3}{|l|}{ Solute $(\mathrm{Cd})$ parameters } \\
\hline $\begin{array}{l}\text { Adsorption isotherm coefficient of } \mathrm{Cd}, \mathrm{cm}^{3} \mathrm{~g}^{-1} \\
\text { Cd adsorption rate to mobile colloids, } \mathrm{h}^{-1} \\
\text { Cd desorption rate from mobile colloids, } \mathrm{h}^{-1} \\
\text { Cd adsorption rate to immobile colloids, } \mathrm{h}^{-1} \\
\text { Cd desorption rate from immobile colloids, } \mathrm{h}^{-1} \\
\text { Cd first-order rate constant for kinetic sorption, } h^{-1}\end{array}$ & $\begin{array}{l}K_{\mathrm{d}} \\
\boldsymbol{k}_{\text {amc }} \\
\boldsymbol{k}_{\mathrm{dmc}} \\
\boldsymbol{k}_{\text {aic }} \\
\boldsymbol{k}_{\mathrm{dic}} \\
\omega\end{array}$ & $\begin{array}{c}2.29 \\
2.30 \dagger \\
1.28 \dagger \\
18.7 \\
0.00 \\
0.25\end{array}$ \\
\hline
\end{tabular}

$\dagger$ Independently determined from a batch kinetic study in the absence of aquifer media (Pang and Šimůnek, 2006). 

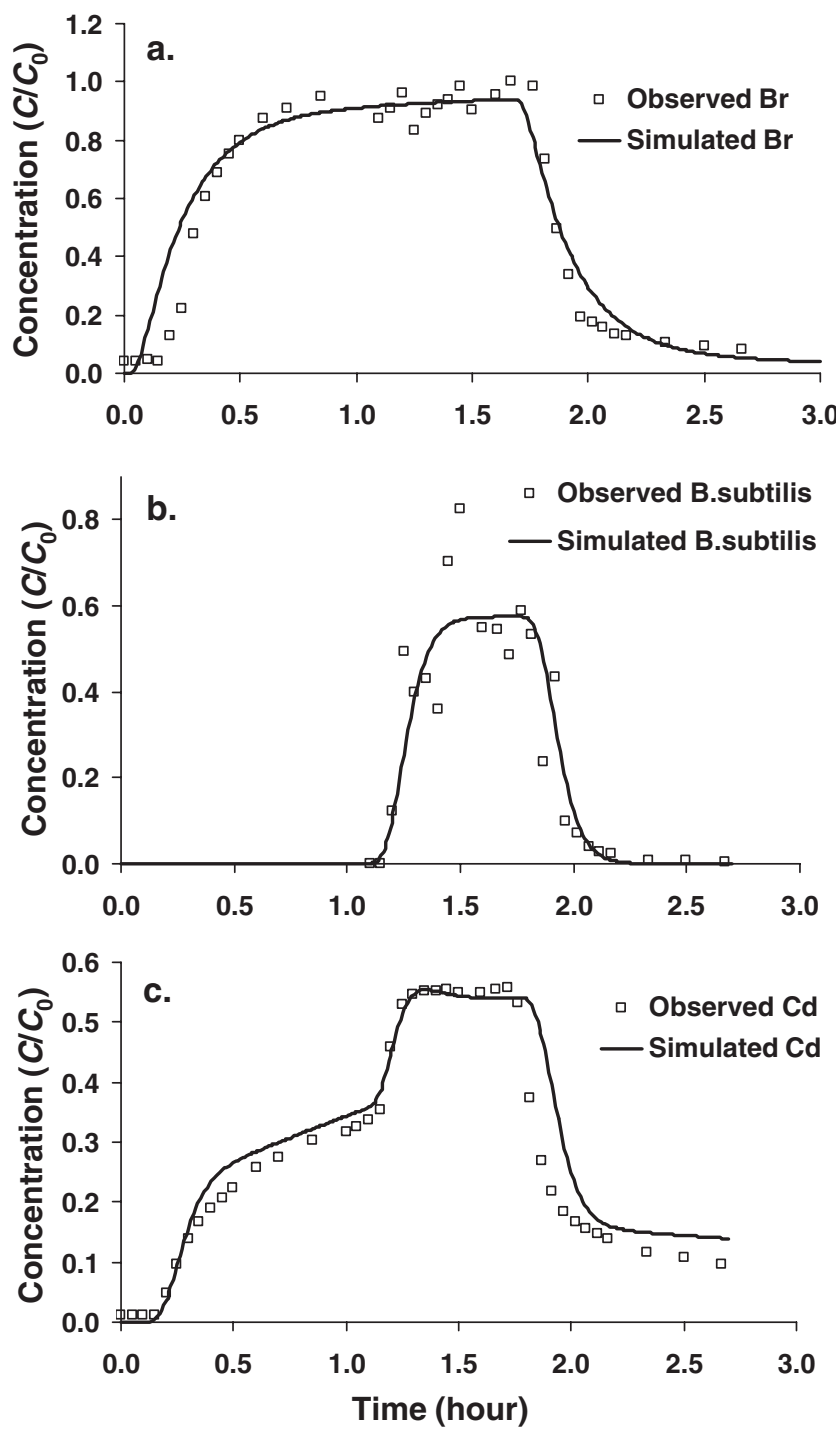

Fig. 3. (a) Observed and simulated Br, (b) Bacillus subtilis spores, and (c) Cd breakthrough curves for the column experiment of Pang et al. (2005).

the experimental set up, batch studies, as well as more examples of model experimental validation involving Cd transport with either B. subtilis spores or Escherichia coli.

\section{SENSITIVITY ANALYSIS}

A sensitivity analysis can be one of the most powerful uses of complex transport models. Such an analysis permits a systematic evaluation of the impact of various model parameters (both transport and reactive), and initial and boundary conditions on the model output. The results of a sensitivity analysis provide insight into the relative importance of individual reactions within a complex geochemical system. These results can thus help one to identify the most important parameters and processes, and thus help guide allocation of resources for laboratory and field investigations (Šimůnek and Valocchi, 2002).
In the sensitivity analysis here we assume that all physical properties, such as porosity, bulk density, water flux, dispersivity, and pore-water velocity are the same as for the column experiment discussed above for B. subtilis spores and Cd. Since the sensitivity of colloid BTCs to various parameters and processes, such as straining and size exclusion, was presented elsewhere (e.g., Bradford et al., 2003), we evaluate here only the sensitivity of model output to the various solute transport parameters.

In this section we evaluate the effects of the solute sorption coefficients on the solute BTC. The analysis considers the same properties for colloids as before (Table 4). We assume that the column is fully saturated and that all pores are accessible to colloids. We further assume that solute sorption to almost all sorption sites of the solid phase is kinetic $(f=0.01)$ and that the distribution coefficient $K_{\mathrm{d}}$ is equal to $2.5 \mathrm{~cm}^{3} \mathrm{~g}^{-1}$ (and 0 , 1 , and 2.5 in the sensitivity analysis). The adsorption rate of contaminant to mobile colloids is considered to be equal to the adsorption rate to immobile colloids (i.e., $\left.k_{\mathrm{amc}}=k_{\mathrm{aic}}\right)$ and, similarly, the desorption rate from mobile colloids is assumed to be equal to the desorption rate from immobile colloids (i.e., $k_{\mathrm{dmc}}=k_{\mathrm{dic}}$ ). While colloids were applied during the time interval between 1 and $1.9 \mathrm{~h}$, solute was applied between 0 and $1.9 \mathrm{~h}$.

In the first analysis we assumed that both the adsorption and desorption coefficients were constant (i.e., $k_{\mathrm{amc}}=k_{\mathrm{dmc}}=10 \mathrm{~h}^{-1}$ ) and varied the solute distribution coefficient $K_{\mathrm{d}}$ from 0 (no retardation) to 1 , and $2.5 \mathrm{~cm}^{3} \mathrm{~g}^{-1}$. In the second analysis we kept constant $K_{\mathrm{d}}\left(=2.5 \mathrm{~cm}^{3} \mathrm{~g}^{-1}\right)$ and $k_{\mathrm{dmc}}\left(=1 \mathrm{~h}^{-1}\right)$ and changed the adsorption coefficient $k_{\text {amc }}$ from 1 to 10 , and $50 \mathrm{~h}^{-1}$. Finally, in the last analysis, we kept constant $K_{\mathrm{d}}\left(=2.5 \mathrm{~cm}^{3}\right.$ $\left.\mathrm{g}^{-1}\right)$ and $k_{\mathrm{amc}}\left(=10 \mathrm{~h}^{-1}\right)$ values, but varied the value of $k_{\mathrm{dmc}}$ from 0.1 to 1 , and $10 \mathrm{~h}^{-1}$.

The colloid BTCs were the same in all three runs (Fig. 4). Figure 4 (top) shows additionally solute BTCs for three different values of $K_{\mathrm{d}}$. Recall that almost all sorption sites are kinetic and thus that the distribution coefficient does not lead to a retardation of the solute

Table 4. Parameter values used in the sensitivity analysis of colloid and solute breakthrough curves evaluating effects of various solute sorption coefficients. Parameter values in parenthesis were used in alternative runs in the sensitivity analyses.

\begin{tabular}{|c|c|c|}
\hline Description & Parameter & Value \\
\hline \multicolumn{3}{|c|}{ Colloid parameters } \\
\hline $\begin{array}{l}\text { First-order colloid attachment } \\
\text { coefficient, } h^{-1}\end{array}$ & $\boldsymbol{k}_{\mathrm{ac}}$ & 1.97 \\
\hline $\begin{array}{l}\text { First-order colloid detachment } \\
\text { coefficient, } h^{-1}\end{array}$ & $k_{\mathrm{dc}}$ & 0.0001 \\
\hline $\begin{array}{l}\text { Water saturation that is not accessible } \\
\text { to mobile colloids }\end{array}$ & $\gamma$ & $\mathbf{0}$ \\
\hline Water saturation & $S_{\mathbf{w}}$ & 1 \\
\hline \multicolumn{3}{|c|}{ Solute parameters } \\
\hline Distribution coefficient, $\mathrm{cm}^{3} \mathrm{~g}^{-1}$ & $K_{d}$ & $2.5(0,1,2.5)$ \\
\hline Mass transfer coefficient, $h^{-1}$ & $\omega$ & 0.3 \\
\hline $\begin{array}{l}\text { Fraction of exchange sites assumed } \\
\text { to be in equilibrium with the } \\
\text { solution phase }\end{array}$ & $f$ & 0.01 \\
\hline $\begin{array}{l}\text { First-order attachment coefficient to } \\
\text { mobile and immobile colloids, }{ }^{-1}\end{array}$ & $k_{\text {amc }}, k_{\text {aic }}$ & $10(1,10,50)$ \\
\hline $\begin{array}{l}\text { First-order detachment coefficient from } \\
\text { mobile and immobile colloids, } h^{-1}\end{array}$ & $k_{\text {dmc }}, k_{\text {dic }}$ & $10(0.1,1,10)$ \\
\hline
\end{tabular}



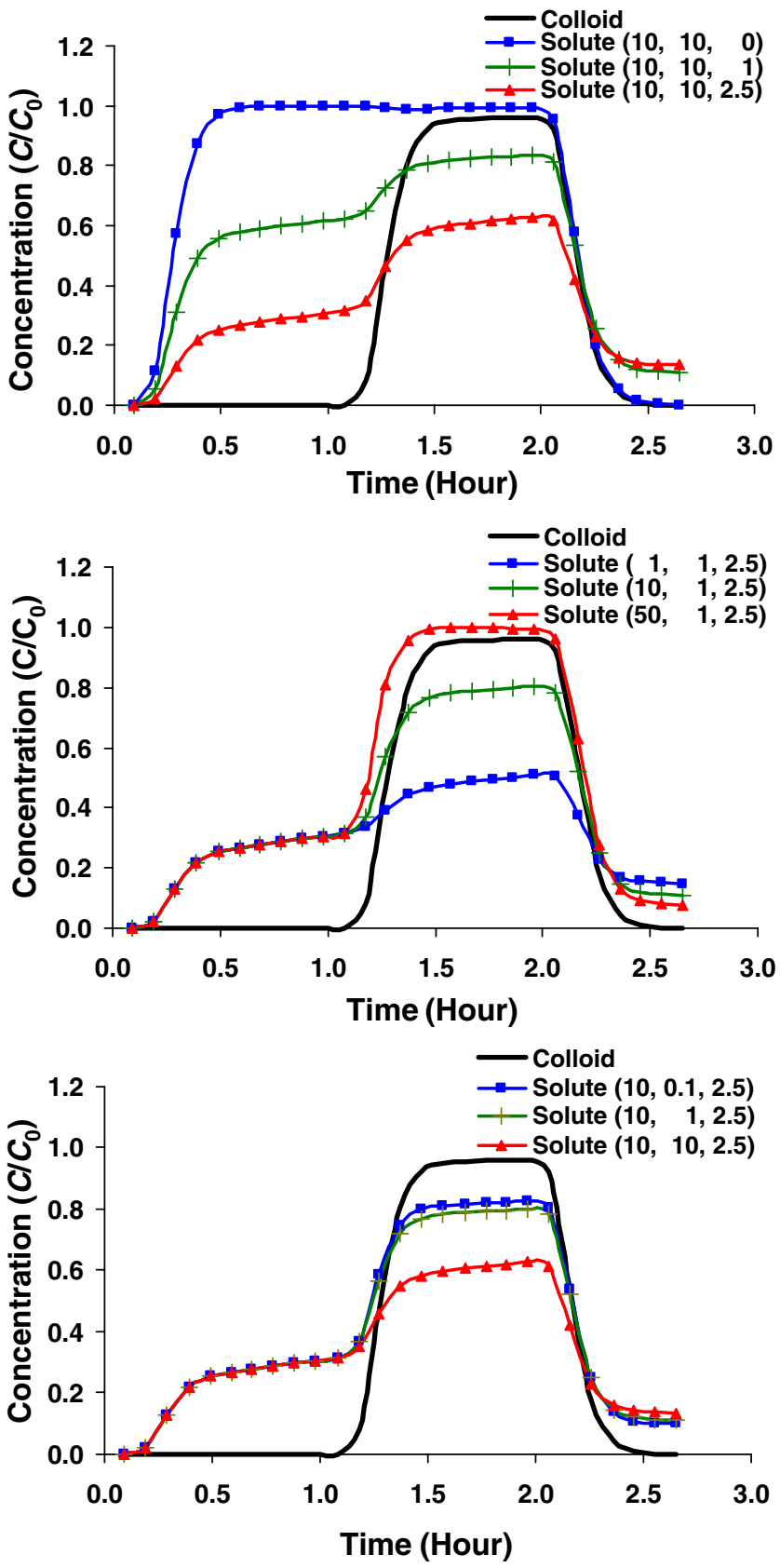

Fig. 4. Sensitivity of simulated breakthrough curves to the (top) distribution coefficient $K_{d}$; (middle) adsorption coefficients to mobile and immobile colloids $\boldsymbol{k}_{\text {amc }}$ and $\boldsymbol{k}_{\text {aic }}$, respectively; and (bottom) desorption coefficients from mobile and immobile colloids $\boldsymbol{k}_{\mathrm{dmc}}$ and $k_{\text {dic }}$, respectively. The first position in parentheses in the legend represents $k_{\mathrm{amc}}$ and $k_{\text {aic }}$, the second $k_{\mathrm{dmc}}$ and $k_{\mathrm{dic}}$, and the third $K_{\mathrm{d}}$.

front. Kinetic adsorption to the solid phase leads to a gradual increase in solute concentration after arrival of the solute front, and an additional gradual increase in concentration after arrival of the colloid front. For the case of no adsorption to the solid phase (i.e., $K_{\mathrm{d}}=0$ ), solute concentrations quickly reached unit relative concentration after arrival of the solute front, and stayed at this level until the end of the solute pulse. Colloids did not have any effect on the solute breakthrough for this set of solute transport parameters since solute was not retarded and thus its transport cannot be ac- celerated by colloids unless they are excluded from some part of the pore space and travel faster than unretarded solute. The effects of colloids on solute transport become apparent when solute is kinetically sorbed. Increasing the kinetic sorption coefficient of the solute produced a more pronounced effect of colloids on solute transport (Fig. 4, top).

A different picture is obtained when sorption to the solid phase is assumed constant $\left(K_{\mathrm{d}}=2.5 \mathrm{~cm}^{3} \mathrm{~g}^{-1}\right)$, but the adsorption coefficient to the colloids $\left(k_{\mathrm{amc}}=k_{\mathrm{aic}}=1\right.$, 10 , or $50 \mathrm{~h}^{-1}$ ) is varied. The initial phase of the solute concentration BTC was the same for all three runs (Fig. 4, middle) since all solute transport parameters characterizing interactions with the soil were the same. Dramatic changes occurred only after the arrival of colloids since sorption rates to the colloids were different for the three runs. The higher the adsorption rate to the colloids, the higher the peaks of the solute concentration BTC as a consequence of more solute arriving at the end of the column sorbed to mobile colloids.

Similar results were obtained when varying the desorption rates from the mobile and the immobile colloids $\left(k_{\mathrm{dmc}}=k_{\mathrm{dic}}=0.1,1\right.$, or $\left.10 \mathrm{~h}^{-1}\right)$. We obtained again the same initial phase of the solute concentration BTC for all three runs (Fig. 4, bottom). Then due to relatively high sorption to both mobile and immobile colloids, concentrations relatively quickly increased with arriving colloids. Due to different desorption rates from the colloids, the plateaus of the solute concentration BTCs were at different levels.

\section{SUMMARY}

We developed a one-dimensional numerical model based on the HYDRUS-1D software package that incorporates various processes associated with colloid and colloid-facilitated solute transport in variably saturated porous media. The numerical model accounts for transient variably saturated water flow and for both colloid and solute movement due to convection, diffusion, and dispersion, as well as for solute movement facilitated by colloid transport. The colloid transport module additionally considers the processes of attachment/detachment to/ from the solid phase and/or the air-water interface. A unique feature of our colloid-facilitated solute transport model is that it accounts for size exclusion and depthdependent straining.

The solute transport module uses the concept of twosite sorption to describe nonequilibrium adsorptiondesorption reactions to the solid phase. The module further assumes that contaminants can be sorbed onto surfaces of both deposited and mobile colloids, thus fully accounting for the dynamics of colloid transfer between different phases. While a majority of models for colloidfacilitated solute transport assume that the number of colloids with respect to the contaminant is large and that kinetic reaction coefficients are not dependent on the number of colloids in the system, our newly developed model accounts for a variable number of colloids in the system; this since colloids may be mobilized (or immobilized) due to changing chemical or hydrological con- 
ditions. Our model can also account for different transport velocities of colloids and solute due to the size exclusion of colloids from small pores.

The use of the model was demonstrated using experimental data from a saturated column experiment, conducted to investigate the transport of $\mathrm{Cd}$ in the presence of Bacillus subtilis spores. We also presented a brief sensitivity analysis of the model to selected reaction parameters characterizing various sorption and desorption coefficients.

Our future work will involve further verification of the code using experimental data derived for more complex conditions, such as transient water flow with mobilization and immobilization of colloids, with colloids interacting with the air-water interface and/or being excluded from part of the pore space.

\section{APPENDIX: LIST OF VARIABLES}

$A_{\text {aw }}$

air-water interfacial area per unit volume $\left[\mathrm{L}^{2} \mathrm{~L}^{-3}\right]$ dissolved-contaminant concentration in the aqueous phase $\left[\mathrm{M} \mathrm{L}^{-3}\right]$

$C_{\mathrm{c}} \quad$ colloid concentration in the aqueous phase $\left[\mathrm{n} \mathrm{L}^{-3}\right]$

$C_{\mathrm{c}}{ }^{\text {ref }}$ reference concentration of colloids for which the sorption rate $k_{\text {amc }}$ is valid $\left[\mathrm{M} \mathrm{L}^{-3}\right.$ ]

$d_{50} \quad$ median grain size of the porous media $[L]$

$D$ dispersion coefficient for contaminants in solution $\left[\mathrm{L}^{2} \mathrm{~T}^{-1}\right]$

$D_{\text {c }} \quad$ dispersion coefficient for colloids $\left[\mathrm{L}^{2} \mathrm{~T}^{-1}\right]$

$f \quad$ fraction of exchange sites assumed to be in equilibrium with the solution phase [-]

$f_{\mathrm{a}} \quad$ fraction of the air-water interfacial area that is available for attachment [-]

$f_{\mathrm{s}} \quad$ fraction of the solid surface area that is available for attachment [-]

gravitational acceleration $\left[\mathrm{L} \mathrm{T}^{-2}\right]$

pressure head [L]

$h$

$k_{\text {ac }}$ first-order colloid attachment coefficient $\left[\mathrm{T}^{-1}\right]$

$k_{\text {aac }}$ adsorption rate to colloids at the air-water interface $\left[\mathrm{T}^{-1}\right]$

$k_{\text {aca }}$ first-order colloid attachment coefficient to the airwater interface $\left[\mathrm{T}^{-1}\right]$

$k_{\text {aic }} \quad$ adsorption rate to immobile colloids [ $\left.\mathrm{T}^{-1}\right]$

$k_{\text {amc }} \quad$ adsorption rate to mobile colloids $\left[\mathrm{T}^{-1}\right]$

$k_{\mathrm{dc}} \quad$ first-order colloid detachment coefficients [ $\left.\mathrm{T}^{-1}\right]$

$k_{\mathrm{dac}}$ desorption rate from colloids at the air-water interface $\left[\mathrm{T}^{-1}\right]$

$k_{\text {dca }}$ first-order colloid detachment coefficient from the air-water interface $\left[\mathrm{T}^{-1}\right]$

$k_{\text {dic }}$ desorption rate from immobile colloids $\left[\mathrm{T}^{-1}\right]$

$k_{\mathrm{dmc}} \quad$ desorption rate from mobile colloids $\left[\mathrm{T}^{-1}\right]$

$k_{\text {str }} \quad$ first-order straining coefficient $\left[\mathrm{T}^{-1}\right]$

$K \quad$ unsaturated hydraulic conductivity [ $\left.\mathrm{LT}^{-1}\right]$

$K_{\text {rc }} \quad$ relative hydraulic conductivity of the colloid-accessible pores [-]

$K_{\text {rw }} \quad$ relative hydraulic conductivity of the entire pore space [-]

$P_{\mathrm{aw}} \quad$ air-water capillary pressure $\left[\mathrm{M} \mathrm{L}^{-1} \mathrm{~T}^{-2}\right]$

$R \quad$ various chemical and biological reactions, such as degradation and production, for contaminant $\left[\mathrm{M} \mathrm{L}^{-3} \mathrm{~T}^{-1}\right]$

$R_{\text {aca }} \quad$ various chemical and biological reactions of attached colloids to the air-water interface $\left[\mathrm{n} \mathrm{L}^{-3} \mathrm{~T}^{-1}\right]$

$R_{\mathrm{ac}} \quad$ various reactions for contaminant sorbed to colloids at the air-water interface $\left[\mathrm{M} \mathrm{L}^{-3} \mathrm{~T}^{-1}\right]$

$R_{\mathrm{c}} \quad$ various chemical and biological reactions for colloids $\left[\mathrm{n} \mathrm{L}^{-3} \mathrm{~T}^{-1}\right]$
$R_{\text {ic }} \quad$ various reactions for contaminant sorbed to immobile colloids $\left[\mathrm{M} \mathrm{L}^{-3} \mathrm{~T}^{-1}\right]$

$R_{\text {mc }} \quad$ various chemical and biological reactions for contaminant sorbed to mobile colloids [ $\mathrm{M} \mathrm{L}^{-3} \mathrm{~T}^{-1}$ ]

$R_{\mathrm{sc}} \quad$ various chemical and biological reactions acting on kinetically attached colloids to the matrix $\left[\mathrm{n} \mathrm{L}^{-3} \mathrm{~T}^{-1}\right]$

$R_{\text {sk }} \quad$ various chemical and biological reactions of the kinetically sorbed contaminant $\left[\mathrm{M} \mathrm{L}^{-3} \mathrm{~T}^{-1}\right]$

$q \quad$ volumetric water density for the contaminant $\left[\mathrm{L} \mathrm{T}^{-1}\right]$

$q_{\text {c }} \quad$ volumetric water flux density for colloids [ $\mathrm{L} \mathrm{T}^{-1}$ ]

$S \quad$ sink term $\left[\mathrm{L}^{3} \mathrm{~L}^{-3} \mathrm{~T}^{-1}\right]$

$S_{\text {ac }}$ contaminant concentration sorbed to immobile (attached to the air-water interface) colloids $\left[\mathrm{M} \mathrm{n}^{-1}\right]$

$S_{\text {c }} \quad$ colloid concentrations adsorbed to the solid phase $\left[\mathrm{n} \mathrm{M}^{-1}\right]$

$S_{\mathrm{c}}{ }^{\text {ref }} \quad$ reference concentration of immobile colloids for which the sorption rate $k_{\text {aic }}$ is valid $\left[\mathrm{n} \mathrm{M}^{-1}\right.$ ]

$S_{\mathrm{c}}$ att $\quad$ solid-phase concentrations of attached colloids [n M $\left.{ }^{-1}\right]$

$S_{\mathrm{c}}$ max maximum solid-phase colloid concentration $\left[\mathrm{n} \mathrm{M}^{-1}\right]$

$S_{\mathrm{c}}^{\text {str }} \quad$ solid-phase concentration of strained colloids $\left[\mathrm{n} \mathrm{M}^{-1}\right]$

$S_{\mathrm{e}} \quad$ contaminant concentration sorbed instantaneously to the solid phase $\left[\mathrm{M} \mathrm{M}^{-1}\right]$

$S_{\text {ic }} \quad$ contaminant concentration sorbed to immobile (attached to the solid phase) colloids $\left[\mathrm{M} \mathrm{N}^{-1}\right]$

$S_{\mathrm{k}} \quad$ contaminant concentration sorbed kinetically to the solid phase $\left[\mathrm{M} \mathrm{M}^{-1}\right]$

$S_{\mathrm{mc}} \quad$ contaminant concentration sorbed to mobile colloids $\left[\mathrm{M} \mathrm{n}^{-1}\right]$

$S_{\mathrm{w}} \quad$ soil water saturation [-]

$t \quad$ time [T]

$x \quad$ spatial coordinate [L] (positive upward)

$\beta \quad$ fitting parameter [-]

$\gamma \quad$ water saturation that is not accessible to mobile colloids [-]

$\Gamma_{c} \quad$ colloid concentrations adsorbed to the air-water interface $\left[\mathrm{n} \mathrm{L}^{-2}\right]$

$\Gamma_{\mathrm{c}}^{\mathrm{ref}} \quad$ reference concentration of immobile colloids for which sorption rate $k_{\text {aac }}$ is valid [ $\mathrm{n} \mathrm{L}^{-2}$ ]

$\varepsilon \quad$ porosity $\left[\mathrm{L}^{3} \mathrm{~L}^{-3}\right]$

$\mu_{c} \quad$ first-order rate constant for solutes in the colloid phase $\left[\mathrm{T}^{-1}\right]$

$\mu_{\mathrm{s}} \quad$ first-order rate constant for solutes in the solid phase $\left[\mathrm{T}^{-1}\right]$

$\mu_{\mathrm{w}} \quad$ first-order rate constant for solutes in the liquid phase $\left[\mathrm{T}^{-1}\right]$

$\psi_{\text {aca }}$ dimensionless colloid retention function for the airwater interface [-]

$\psi_{\mathrm{g}} \quad$ parameter adjusting the sorption rate to the number of colloids at the air-water interface [-]

$\psi_{i} \quad$ parameter adjusting the sorption rate to the number of immobile colloids present

$\psi_{\mathrm{m}} \quad$ parameter adjusting the sorption rate to the number of mobile colloids present

$\psi_{\mathrm{s}} \quad$ dimensionless colloid retention function [-]

$\Psi \quad(C)$ adsorption isotherm $\left[\mathrm{M} \mathrm{M}^{-1}\right]$

$\omega \quad$ first-order rate constant $\left[\mathrm{T}^{-1}\right]$

$\sigma_{\text {aw }}$ air-water surface tension $\left[\mathrm{M} \mathrm{T}^{-2}\right]$

$\theta \quad$ volumetric water content $\left[\mathrm{L}^{3} \mathrm{~L}^{-3}\right]$

$\theta_{\mathrm{w}} \quad$ volumetric water content accessible to colloids $\left[\mathrm{L}^{3} \mathrm{~L}^{-3}\right]$

$\rho \quad$ bulk density $\left[\mathrm{M} \mathrm{L}^{-3}\right]$

$\rho_{\mathrm{w}} \quad$ density of water $\left[\mathrm{M} \mathrm{L}^{-3}\right]$

\section{ACKNOWLEDGMENTS}

The work was supported by the Terrestrial Sciences Program of the Army Research Office (Terrestrial Processes and Landscape Dynamics And Terrestrial System Modeling and Model Integration), project number $45690 \mathrm{EV}$. 


\section{REFERENCES}

Adamczyk, Z., B. Siwek, M. Zembala, and P. Belouschek. 1994. Kinetics of localized adsorption of colloid particles. Adv. Colloid Interface Sci. 48:151-280.

Bekhit, H.M., and A.E. Hassan. 2005. Two-dimensional modeling of contaminant transport in porous media in the presence of colloids. Adv. Water Resourc. 28:1320-1335.

Bradford, S.A., M. Bettahar, J. Šimůnek, and M.Th. van Genuchten. 2004. Straining and attachment of colloids in physically heterogeneous porous media. Vadose Zone J. 3:384-394.

Bradford, S.A., and F.J. Leij. 1997. Estimating interfacial areas for multi-fluid soil systems. J. Contam. Hydrol. 27:83-105.

Bradford, S.A., J. Šimůnek, M. Bettahar, M.Th. van Genuchten, and S.R. Yates. 2003. Modeling colloid attachment, straining, and exclusion in saturated porous media. Environ. Sci. Technol. 37:2242-2250.

Bradford, S.A., J. Šimůnek, M. Bettahar, M.Th. van Genuchten, and S.R. Yates. 2006. Significance of straining in colloid deposition: Evidence and implications, Water Resour. Res. (in review).

Bradford, S.A., S.R. Yates, M. Bettahar, and J. Simůnek. 2002. Physical factors affecting the transport and fate of colloids in saturated porous media. Water Resour. Res. 38(12):1327 doi:10.1029/ 2002WR001340.

Burdine, N.T. 1953. Relative permeability calculations from pore-size distribution data. Petr. Trans. Am. Inst. Mining Metall. Eng. 198:71-77.

Carsel, R.F., and R.S. Parrish. 1988. Developing joint probability distributions of soil water retention characteristics. Water Resour. Res. 24:755-769.

Corapcioglu, M.Y., and H. Choi. 1996. Modeling colloid transport in unsaturated porous media and validation with laboratory column data. Water Resour. Res. 32:3437-3449.

Corapcioglu, M.Y., and S. Jiang. 1993. Colloid-facilitated groundwater contaminant transport. Water Resour. Res. 29(7):2215-2226.

Cumbie, D.H., and L.D. McKay. 1999. Influence of diameter on particle transport in a fractured shale saprolite. J. Contam. Hydrol. 37:139-157.

DeNovio, N.M., J.E. Saiers, and J.N. Ryan. 2004. Colloid movement in unsaturated porous media: Recent advances and future directions. Vadose Zone J. 3:338-351.

Deshpande, P.A., and D.R. Shonnard. 1999. Modeling the effects of systematic variation in ionic strength on the attachment kinetics of Pseudomonas fluorescens UPER-I in saturated sandy media. Water Resour. Res. 35(5):1619-1627.

Doherty, J. 1994. PEST. Watermark Computing, Corinda, Australia.

Dunnivant, F.M., P.M. Jardine, D.L. Taylor, and J.F. McCarthy. 1992. Cotransport of cadmium and hexachlorobiphenyl by dissolved organic carbon through columns containing aquifer material. Environ. Sci. Technol. 26:360-368.

Ginn, T. R. 1995. A brief review of bacterial transport in natural porous media. PNL-10876, UC-402. Pacific Northwest Natl. Lab., Richland, WA.

Ginn, T.R. 2002. A travel time approach to exclusion on transport in porous media. Water Resour. Res. 38:1041 doi:10.1029/2001WR000865.

Grolimund, D., M. Borkovec, K. Barmettler, and H. Sticher. 1996. Colloid-facilitated transport of strongly sorbing contaminants in natural porous media; a laboratory column study. Environ. Sci. Technol. 30:3118-3123.

Gvirtzman, H., and S.M. Gorelick. 1991. Dispersion and advection in unsaturated porous media enhanced by anion exclusion. Nature (London) 352:793-795.

Hanselman, T.A., D.A. Graetz, and A.C. Wilkie. 2003. Manure-borne estrogens as potential environmental contaminants: A review. Environ. Sci. Technol. 37:5471-5478.

Harter, T., S. Wagner, and E.R. Atwill. 2000. Colloid transport and filtration of Cryptosporidium parvum in sandy soils and aquifer sediments. Environ. Sci. Technol. 34:62-70.

Harvey, R.W., and S.P. Garabedian. 1991. Use of colloid filtration theory in modeling movement of bacteria through a contaminated sandy aquifer. Environ. Sci. Technol. 25:178-185.

Hornberger, G.M., A.L. Mills, and J.S. Herman. 1992. Bacterial transport in porous media: Evaluation of a model using laboratory observations. Water Resour. Res. 28:915-938.

Jiang, S., and M.Y. Corapcioglu. 1993. A hybrid equilibrium model for solute transport in porous medium in the presence of colloids. Colloids Surf. A. 73:275-286.
Johnson, P.R., and M. Elimelech. 1995. Dynamics of colloid deposition in porous media: Blocking based on random sequential adsorption. Langmuir 11:801-812.

Kan, A.T., and M.B. Tomson. 1990. Ground water transport of hydrophobic organic compounds in the presence of dissolved organic matter. Environ. Toxicol. Chem. 9:253-263.

Kim, J.I., P. Zeh, and B. Delakowitz. 1992. Chemical interactions of actinide ions with groundwater colloids in Gorleben aquifer systems. Radiochim. Acta 58-9:147-154.

Kretzschmar, R., M. Borkovec, D. Grolimund, and M. Elimelech. 1999. Mobile subsurface colloids and their role in contaminant transport. Adv. Water Resour. 66:121-193.

Krupp, H.K., J.W. Biggar, and D.R. Nielsen. 1972. Relative flow rates of salt and water in soil. Soil Sci. Soc. Am. Proc. 36:412-417.

Li, X., T.D. Scheibe, and W.P. Johnson. 2004. Apparent decreases in colloid deposition rate coefficients with distance of transport under unfavorable deposition conditions: A general phenomenon. Environ. Sci. Technol. 38:5616-5625.

Lindqvist, R., and C.G. Enfield. 1992. Biosorption of dichlorodiphenyltri-chloroethane and hexachlorobenzene in groundwater and its implications for facilitated transport. Appl. Environ. Microbiol. 58:2211-2218.

Logan, B.E., D.G. Jewett, R.G. Arnold, E.J. Bouwer, and C.R. O'Melia. 1995. Clarification of clean-bed filtration models. J. Environ. Eng. 121:869-873.

Magee, B.R., L.W. Lion, and A.T. Lemley. 1991. Transport of dissolved organic macromolecules and their effect on the transport of phenanthrene in porous media. Environ. Sci. Technol. 25:323-331.

Mansfeldt, T., H. Leyer, K. Barmettler, and R. Kretzschmar. 2004. Cyanide leaching from soil developed from coking plant purifier waste as influenced by citrate. Vadose Zone J. 3:471-479.

Marquardt, D.W. 1963. An algorithm for least-squares estimation of nonlinear parameters. SIAM J. Appl. Math. 11:431-441.

McCarthy, J.F., and J.M. Zachara. 1989. Subsurface transport of contaminants. Environ. Sci. Technol. 23(5):496-502.

McDowell-Boyer, L.M., J.R. Hunt, and N. Sitar. 1986. Particle transport through porous media. Water Resour. Res. 22:1901-1921.

Mills, W.M., S. Liu, and F.K. Fong. 1991. Literature review and model (COMET) for colloid/metals transport in porous media. Ground Water 29:199-208.

Noell, A.L., J.L. Thompson, M.Y. Corapcioglu, and I.R. Triay. 1998. The role of silica colloids on facilitated cesium transport through glass bead columns and modeling. J. Contam. Hydrol. 31(1-2):23-56.

Pang, L., M. Close, M. Noonan, M. Flintoft, and P. van den Brink. 2005. A laboratory study of bacteria-facilitated cadmium transport in alluvial gravel aquifer media. J. Environ. Qual. 34:237-247.

Pang, L., and J. Šimůnek. 2006. Evaluation of bacteria-facilitated solute transport model. Water Resour. Res. (in press).

Rajagopalan, R., and C. Tien. 1976. Trajectory analysis of deep-bed filtration with the sphere-in-cell porous media model. AIChE J. 22:523-533.

Reimus, P.W. 1995. The use of synthetic colloids in tracer transport experiments in saturated rock fractures, LA-13004-T. Los Alamos Natl. Lab., Los Alamos, NM.

Richards, L.A. 1931. Capillary conduction of fluid through porous mediums. Physics 1:318-333.

Rockhold, M.L., R.R. Yarwood, and J.S. Selker. 2004. Coupled microbial and transport processes in soils. Vadose Zone J. 3:368-383.

Ryan, J.N., and M. Elimelech. 1996. Colloid mobilization and transport in groundwater. Colloids Surf. A: Physicochem. Eng. Aspects 107:1-56.

Saiers, J.E., and G.M. Hornberger. 1996. The role of colloidal kaolinite in the transport of cesium through laboratory sand columns. Water Resour. Res. 32(1):33-41.

Saiers, J.E., and J.J. Lenhart. 2003. Ionic-strength effects on colloid transport and interfacial reactions in partially saturated porous media. Water Resour. Res. 39:1256 doi:10.1029/2002WR001887.

Scheibe, T.D., and B.D. Wood. 2003. A particle-based model of size or anion exclusion with application to microbial transport in porous media. Water Resour. Res. 39(4):1080 doi:10.1029/200IWRO01223.

Šimůnek, J., M. Šejna, and M.Th. van Genuchten. 1998. The HYDRUS-1D software package for simulating the one-dimensional movement of water, heat, and multiple solutes in variablysaturated media, Version 2.0. IGWMC- TPS- 70. Int., Ground Water Modeling Center, Colorado School of Mines, Golden. 
Šimůnek, J., and A.J. Valocchi. 2002. Geochemical transport. p. 1511-1536 In J.H. Dane and G.C. Topp (ed.) Methods of soil analysis. Part 1. Physical methods. 3rd ed. SSSA, Madison, WI.

Sinton, L.W., M.J. Noonan, R.K. Finlay, L. Pang, and M.E. Close. 2000. Transport and attenuation of bacteria and bacteriophages in an alluvial gravel aquifer. N. Z. J. Mar. Freshwater Res. 34(1): 175-186.

Thiele-Bruhn, S. 2003. Pharmaceutical antibiotic compounds in soilsA review. J. Plant Nutr. Soil Sci. 166:145-167.

Thompson, S.S., and M.V. Yates. 1999. Bacteriophage inactivation at the air-water-solid interface in dynamic batch systems. Appl. Environ. Microbiol. 65:1186-1190.

Tien, C. 1989. Granular filtration of aerosols and hydrosols. Butterworth, London.

Tien, C., and H. Chiang. 1985. Dynamics of deep-bed filtration. II. Experiment. AIChE J. 31(8):1360-1371.

Tolls, J. 2001. Sorption of veterinary pharmaceuticals in soils: A review. Environ. Sci. Technol. 35:3397-3406.

Tufenkji, N., and M. Elimelech. 2004. Correlation equation for predicting single-collector efficiency in physiochemical filtration in saturated porous media. Environ. Sci. Technol. 38:529-536.

Tufenkji, N., and M. Elimelech. 2005. Breakdown of colloid filtration theory: Role of the secondary energy minimum and surface charge heterogeneities. Langmuir 21:841-852.

van de Weerd, H., and A. Leijnse. 1997. Assessment of the effect of kinetics on colloid facilitated radionuclide transport in porous media. J. Contam. Hydrol. 26:245-256. van Genuchten, M.Th. 1980. A closed-form equation for predicting the hydraulic conductivity of unsaturated soils. Soil Sci. Soc. Am. J. 44:892-898.

van Genuchten, M.Th., and J. Šmůnek. 2004. Integrated modeling of vadose zone flow and transport processes. p. 37-69, x-xi. In R.A. Feddes et al. (ed.) Proc. Unsaturated Zone Modelling: Progress, Challenges and Applications, Wageningen UR Frontis Ser., Vol., 6, Wageningen, the Netherlands. 3-5 Oct. 2004. Kluwer Academic Publ., Dordrecht, the Netherlands.

van Genuchten, M.Th., and R.J. Wagenet. 1989. Two-site/two-region models for pesticide transport and degradation: Theoretical development and analytical solutions. Soil Sci. Soc. Am. J. 53: 1303-1310.

Vinten, A.J.A., B. Yaron, and P.H. Nye. 1983. Vertical transport of pesticides into soil when adsorbed on suspended particles. J. Agric. Food Chem. 31:662-664.

Von Gunten, H.R., V.E. Weber, and U. Krahenbuhl. 1988. The reactor accident at Chernobyl: A possibility to test colloid-controlled transport of radionuclides in a shallow aquifer. J. Contam. Hydrol. 2:237-247.

Wan, J., and T.K. Tokunaga. 1997. Film straining of colloids in unsaturated porous media: Conceptual model and experimental testing. Environ. Sci. Technol. 31:2413-2420.

Wan, J.M., and T.K. Tokunaga. 2002. Partitioning of clay colloids at airwater interfaces. J. Colloid Interface Sci. 247:54-61.

Wan, J., and J.L. Wilson. 1994. Visualization of the role of the gaswater interface on the fate and transport of colloids in porous media. Water Resour. Res. 30:11-23. 